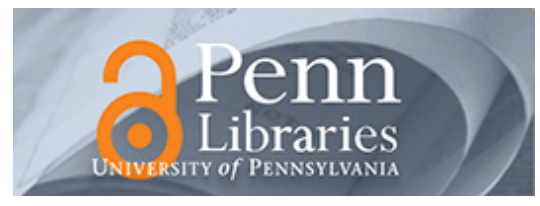

University of Pennsylvania ScholarlyCommons

$11-2006$

\title{
An Empirical Inquiry Into the Relation of Corrective Justice to Distributive Justice
}

\author{
Gregory Mitchell \\ University of Virginia \\ Philip E. Tetlock \\ University of Pennsylvania
}

Follow this and additional works at: https://repository.upenn.edu/mgmt_papers

Part of the Management Sciences and Quantitative Methods Commons

\section{Recommended Citation}

Mitchell, G., \& Tetlock, P. E. (2006). An Empirical Inquiry Into the Relation of Corrective Justice to Distributive Justice. Journal of Empirical Legal Studies, 3 (3), 421-466. http://dx.doi.org/10.1111/ j.1740-1461.2006.00075.x

This paper is posted at ScholarlyCommons. https://repository.upenn.edu/mgmt_papers/294

For more information, please contact repository@pobox.upenn.edu. 


\title{
An Empirical Inquiry Into the Relation of Corrective Justice to Distributive Justice
}

\begin{abstract}
We report the results of three experiments examining the long-standing debate within tort theory over whether corrective justice is independent of, or parasitic on, distributive justice. Using a "hypothetical societies" paradigm that serves as an impartial reasoning device and permits experimental manipulation of societal conditions, we first tested support for corrective justice in a society where individual merit played no role in determining economic standing. Participants expressed strong support for a norm of corrective justice in response to intentional and unintentional torts in both just and unjust societies. The second experiment tested support for corrective justice in a society where race, rather than individual merit, determined economic standing. The distributive justice manipulation exerted greater effect here, particularly on liberal participants, but support for corrective justice remained strong among nonliberal participants, even against a background of racially unjust distributive conditions. The third experiment partially replicated the first experiment and found that the availability of government-funded insurance had little effect on demands for corrective justice. Overall, the results suggest that while extreme distributive injustice can moderate support for corrective justice, the norm of corrective justice often dominates judgments about compensatory duties associated with tortious harms.

Disciplines

Management Sciences and Quantitative Methods
\end{abstract}




\title{
An Empirical Inquiry into the Relation of Corrective Justice to Distributive Justice
}

\author{
Gregory Mitchell \& Philip E. Tetlock*
}

Forthcoming in JOURNAL OF EMPIRICAL LEGAL STUDIES, Volume 3 (2006)

\begin{abstract}
We report the results of three experiments examining the long-standing debate within tort theory over whether corrective justice is independent of, or parasitic on, distributive justice. Using a "hypothetical societies" paradigm that serves as an impartial reasoning device and permits experimental manipulation of societal conditions, we first tested support for corrective justice in a society where individual merit played no role in determining economic standing. Participants expressed strong support for a norm of corrective justice in response to intentional and unintentional torts in both just and unjust societies. The second experiment tested support for corrective justice in a society where race, rather than individual merit, determined economic standing. The distributive justice manipulation exerted greater effect here, particularly on liberal participants, but support for corrective justice remained strong among non-liberal participants, even against a background of racially unjust distributive conditions. The third experiment partially replicated the first experiment and found that the availability of government-funded insurance had little effect on demands for corrective justice. Overall, the results suggest that, while extreme distributive injustice can moderate support for corrective justice, the norm of corrective justice often dominates judgments about compensatory duties associated with tortious harms.
\end{abstract}

\footnotetext{
${ }^{*}$ Mitchell is Professor of Law and E. James Kelly, Jr.-Class of 1965 Research Professor at the University of Virginia School of Law, 580 Massie Road, Charlottesville, VA 22903-1738, greg_mitchell@virginia.edu; Tetlock is Mitchell Professor of Leadership at the Haas School of Business, University of California, Berkeley, 94720-1900, tetlock@haas.berkeley.edu The authors thank Brian Bornstein, Curtis Bridgeman, Paul Edelman, Ted Eisenberg, John Goldberg, Steven Hetcher, Jeff O’Connell, Jeff Rachlinski, Keith Sharfman, an anonymous reviewer, and participants at a Florida State University College of Law Faculty Workshop and a Vanderbilt University Law School Dean's Lunch for helpful comments.
} 


\section{An Empirical Inquiry into the Relation of Corrective Justice to Distributive Justice}

\section{Introduction}

\section{A. Theoretical Treatments of the Relationship Between Corrective and Distributive Justice}

Imagine a man on his way to work who cuts across the property of another man without permission, causing some minor economic harm to the property of the second man. Should the first man compensate the second for the harm done? If your answer is yes, then your response may reflect a notion of corrective justice, which provides, roughly, that a person who wrongfully causes harm to another has a duty to repair the harm. ${ }^{1}$ A positive response may also reflect an underlying assumption about the legitimacy of the second man’s property rights.

To check the influence of your background assumptions, imagine now that the first man was extremely poor but did not deserve his penury and that the second man was extremely rich but did not deserve his wealth. Imagine as well that the act, while wrongful in the sense of being an unauthorized entry onto another's land, resulted in a slight improvement in the justness of the distribution of wealth such as might occur with a trespass to the rich man's property that tramples one of many daisies but obviates the need for the poor man to pay bus fare. Would justice still require that the first man compensate the second under these circumstances? ${ }^{2}$

Theories of corrective justice suggest a variety of answers to this amended hypothetical, for these theories differ significantly in the role that background distributive conditions play in

\footnotetext{
${ }^{1}$ See, e.g., Kim Forde-Mazrui, Taking Conservatives Seriously: A Moral Justification for Affirmative Action and Reparations, 92 CAL. L. REV. 683, 707 (2004). Corrective justice theorists formulate the precise contours of the corrective justice principle differently, and corrective justice theory is only one of a variety of perspectives on the proper response to civil injuries. For an overview of tort theories, see John C.P. Goldberg, Twentieth-Century Tort Theory, 91 GEO. L.J. 513 (2003).

2 This hypothetical and the vignettes used in the experiments reported here were inspired by Coleman's well-known "Rockefeller" thought experiment, in which Coleman asks whether a dreadfully poor person should compensate an extremely wealthy person for an economic injury if the prior distribution was unjust or the injury led to a more just distribution of wealth. See Jules L. Coleman, Risks And Wrongs 304-05 (1992).
} 
founding the principle of corrective justice. "One common view is that corrective justice requires a prior distribution of entitlements upon which to operate, and that its purpose or point is to maintain that distribution; for that reason, [corrective justice] is regarded as both conceptually

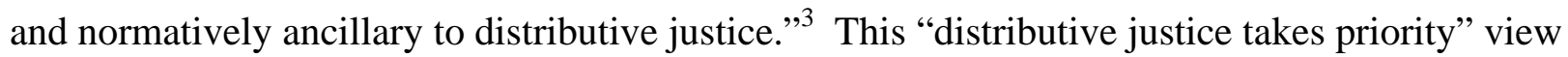
suggests that the poor man in our second hypothetical might escape liability if the parties' initial respective holdings were not justly distributed; upsetting the distribution imposes no duty of rectification because the redistribution promotes a more just arrangement. ${ }^{4}$

Another common view is that corrective justice "protects against actual or threatened interactional injuries to one's person or existing stock of resources regardless of the distributive justice or injustice of the overall division of resources among the parties to the interaction or among the members of the community as a whole." ${ }^{5}$ This independence view, taken prominently (if in different forms) by Benson, Weinrib, and Wright, dictates that the poor man in our second hypothetical remain liable despite his needs or the unfairness with which resources have been allocated. ${ }^{6}$ As Honoré puts it, even the "filthy rich can appeal to corrective justice if their holdings are filched by the grinding poor.",7

\footnotetext{
${ }^{3}$ Stephen R. Perry, On the Relationship Between Corrective and Distributive Justice, in OXFORD ESSAYS IN JuRISPRUDENCE, FourTh SERIES 237, 237 (Jeremy Holder ed., 2000).

${ }^{4}$ See, e.g., Ken Cooper-Stephenson, Corrective Justice, Substantive Equality and Tort Law, in TORT THEORY 48 (Ken Cooper-Stephenson \& Elaine Gibson eds., 1993); Ken Cooper-Stephenson, Economic Analysis, Substantive Equality and Tort Law, in TORT THEORY, supra at 131; James A. Gordley, Tort Law in the Aristotelian Tradition, in PhilosophicAl Foundations of TORT LAW 131 (David G. Owen ed., 1995).

${ }^{5}$ Richard W. Wright, Right, Justice, and Tort Law, in PHILOSOPHICAL FOUNDATIONS OF TORT THEORY, supra note 4, at 159, 171 (1995).

${ }^{6}$ See, e.g., Ernest J. WeInRIB, The IDEA OF PRIVATE LAW 73 (1995); Peter Benson, The Basis of Corrective Justice and Its Relation to Distributive Justice, 77 IowA L. REV. 515 (1992); Ernest J. Weinrib, Corrective Justice, 77 IowA L. REV. 403, 415-16 (1992); Richard W. Wright, Substantive Corrective Justice, 77 IowA L. REV. 625, $705-06$ (1992).

${ }^{7}$ Tony Honoré, The Morality of Tort Law-Questions and Answers, in PHILOSOPHICAL FOUNDATIONS OF TORT LAW, supra note 5, at 73, 84.
} 
Still other corrective justice theorists posit a complementary, but not a necessary, relationship between the two forms of justice. Coleman, for instance, avers that only "real rights" merit protection under corrective justice and that rights are "real" when they have been allocated in approximate accordance with some just distributive criterion (i.e., when society achieves some second- or third-best world in terms of distributive justice) or when they may otherwise be deemed morally legitimate rights. ${ }^{8}$ Coleman’s primary point seems to be that rights and possessions that are not obviously unjust or immoral under a legitimate political system or system that sustains market institutions and social stability should receive the protection of a norm of corrective justice. ${ }^{9}$

Perry similarly posits that corrective justice protects only morally legitimate entitlements and that, while just distribution is one means by which entitlements become legitimate, just distribution is not the only means to legitimation. ${ }^{10}$ Distributive justice is thus a sufficient but not a necessary condition for the legitimacy of holdings, and corrective justice operates only on legitimate holdings. ${ }^{11}$ In addition, Perry doubts that distributive justice can be worked out in individual cases in any satisfactory way (under any dynamic conception of distributive justice, that is ${ }^{12}$ ), but he believes that the apparent legitimacy of an individual's personal and property

\footnotetext{
${ }^{8}$ See Coleman, supra note 2, at 350-54.

${ }^{9}$ Coleman makes clear that the kind of rights and entitlements that satisfy his condition for corrective justice is the "scheme of rights protected by private law in liberal political cultures like our own." Id. at 354.

${ }^{10}$ See Perry, supra note 3, at 254, 257, 262.

${ }^{11}$ Perry excludes a person's interest in life and bodily integrity from the realm of resources subject to distribution. See id. at 256. Once this move is made, then any unified theory of corrective justice that protects both the person and property cannot be ancillary to a theory of distributive justice.

${ }^{12}$ A dynamic theory of justice specifies rules for determining just outcomes (e.g., from each according to his abilities, to each according to his needs) and does not presuppose any particular fixed pattern of distributive outcomes. A static theory of justice, on the other hand, prescribes a particular distributive outcome (e.g., equality of material holdings). As Perry notes, '[t]he most influential contemporary theories of distributive justice are dynamic rather than static." Id. at 245.
} 
rights will be more determinate. ${ }^{13}$ Accordingly, in Perry's corrective justice theory "what matters is not ideal distributive justice but moral legitimacy." ${ }^{\text {14 }}$ However, like Coleman, Perry takes rough distributive justice to be a proxy for the moral legitimacy of property rights. ${ }^{15}$

We may also place within this interdependence category Coleman’s contention that operation of the principle of corrective justice depends on the other practices that exist within a community to compensate for misfortunes. ${ }^{16}$ Here Coleman has in mind background conditions relating to the distribution of risk and responsibility as opposed to the distribution of resources. For example, if a community has decided to allocate losses widely through a taxpayer-funded no-fault insurance scheme, then there should be no need, or at least less need, for a duty to redress harms done and hence no practice of corrective justice in this community. ${ }^{17}$ This displacement of corrective justice by other practices conflicts with the independence view however, which treats corrective justice as an autonomous form of justice that cannot be satisfied by alternative practices that might evolve to mitigate misfortunes. ${ }^{18}$

This interdependence view implies a presumption in favor of the legitimacy of rights and possessions and, thus, a presumption that communities will express a norm of corrective justice in its tort law. But this view leaves open the possibility that a distributive system will be so unjust, and the other sources of rights legitimation so weak, that the normative preconditions for corrective justice and a concomitant body of tort law will not exist. Conversely, the absence of a

\footnotetext{
${ }^{13}$ See id. at 260-61.

${ }^{14} I d$. at 262.

${ }^{15}$ See id. at 261; see also Jules Coleman, The Practice Of Principle 33 \& n.15 (2001).

${ }^{16}$ See Coleman, supra note 2, at 404; Jules L. Coleman, The Practice of Corrective Justice, in PHILOSOPHICAL FOUNDATIONS OF TORT LAW, supra note 4, at 53, 71.

${ }^{17}$ See COLEMAN, supra note 15 , at 71.

${ }^{18}$ See, e.g., Wright, supra note 5, at 179.
} 
tort system and a norm of corrective justice do not mean that a society is unjust. At least in

Coleman's view, a political community might employ alternative loss-rectification practices that do not instantiate the norm of corrective justice but nonetheless are just by other criteria.

In sum, a strong distributive priority view posits that corrective justice has moral force only when a just distribution of resources has been wrongfully disturbed. Corrective justice in this view becomes another way of seeing that distributive justice is done. The independence view posits that corrective justice has moral force when any distribution of resources has been wrongfully disturbed, and it is the duty of the wrongdoer, rather than society at large, to see that corrective justice is done. Corrective justice in this view has autonomous moral force. The interdependence view posits that corrective justice has moral force only when morally legitimate interests have been wrongfully disturbed, but, as applied to many existing polities, this view largely parallels the independence view because it treats the existing allocation of rights and interests as presumptively legitimate.

\section{B. An Experimental Study of the Relationship Between Corrective and Distributive Justice}

These differing views on the relationship between corrective and distributive justice arise primarily from different interpretations of the practices associated with the law of torts, for tort law serves as the data and explanandum and the principle of corrective justice serves as the explanans. ${ }^{19}$ In other words, these interpretive approaches, which seek to develop coherent explanations for the law of torts, find a general moral grounding for tort law in some principle

\footnotetext{
${ }^{19}$ For a discussion of the largely interpretive nature of corrective justice theory, see Goldberg, supra note 1, at 571. While many of the claims of corrective justice theorists have an empirical flavor, the primary goal of corrective justice theory is to make sense of the core of tort law or to find a set of concepts that provide an objective basis for tort law as it is practiced. For instance, Coleman describes his theory of corrective justice as "middle level theory" that is formed by "extracting principles and norms from existing practices, including legal ones," Coleman, supra note 15, at 62, and Weinrib's "juridical conception of corrective justice attempts to exhibit the normative ideas interior to a coherent regime of liability" by looking to "the principles and concepts already present to tort law," Ernest J. Weinrib, Correlativity, Personality, and the Emerging Consensus on Corrective Justice, 2 THEORETICAL INQUIRIES L. 107, 110-11 (2001).
} 
that we may label corrective justice, but these interpretive approaches yield different conclusions about the content, or conditions on the applicability, of this principle.

The present research takes a very different approach to the question of how corrective and distributive justice relate than that usually found within corrective justice theory. Rather than ask how the practices of legal and political institutions reflect the relationship between corrective and distributive justice, the present study directly examines how these two forms of justice interact in individuals' moral reasoning. Specifically, the present research employs an experimental design that creates direct conflicts between corrective and distributive justice that individuals must resolve. By examining how individuals reason through these conflicts, we may gain insight into the sensitivity of corrective justice to background distributive conditions. ${ }^{20}$

This research fits within the larger body of empirical research on public conceptions of justice, a body of work that contains strikingly little study of corrective justice. ${ }^{21}$ Empirical studies of justice may serve both theoretical and practical ends. On the theory side, empirical studies provide the basis for descriptive models of moral reasoning and, if properly designed to tap into relatively impartial moral judgments, can provide support for normative theories of justice or serve as a check on philosopher's intuitions about the judgments that would be made under ideal reasoning conditions. ${ }^{22}$ On the practical side, empirical studies of justice examine how justice concerns influence a wide range of public behaviors, from interpersonal and

\footnotetext{
${ }^{20}$ In this respect, the study directs needed attention at the role of laypersons as potential jurors within the tort system. See Steven Hetcher, The Jury's Out: Social Norms' Misunderstood Role in Negligence Law, 91 GEO. L.J. 633 (2003).

${ }^{21}$ For a notable exception, see NEAL FEIGENSON, LEgAL BLAME 104 (2000). Baron and Ritov examined hypothetical tort decisions but did not discuss the import of their findings for corrective justice theory. See Jonathan Baron \& Ilana Ritov, Intuitions about Penalties and Compensation in the Context of Tort Law, 7 J. RISK \& UNCERTAINTY 17, 31 (1993).

${ }^{22}$ See, e.g., Coleman, supra note 15, at 213; DAVID Miller, Principles OF Social Justice 51 (1999).
} 
employment relations to legal compliance, jury decisions, and voter behavior. Further, to the extent that ethical theories serve as the basis for public policy proposals, empirical studies of justice can shed light on the moral acceptability and political plausibility of such proposals. Work by Finkel and Robinson and Darley, for example, reveals significant areas of divergence between the criminal law and public morality, a gap that may encourage jury nullification and have broader system legitimacy effects. ${ }^{23}$

The primary aim of the present research is to test the competing theoretical claims about the relation of corrective justice to distributive justice, but the findings may yield practically useful information as well. For instance, a finding that corrective justice is insensitive to background distributive conditions would suggest public opposition or indifference to tort reform efforts designed to diminish the role of tort law and give other compensation mechanisms a greater role in misfortune management. To shed further light on the practicality of moves away from a fault-based tort system founded on corrective justice, we examined whether the existence of alternative means of compensating a tort victim, in the form of private or social insurance, affected support for the corrective justice norm.

Due to our own prior justice research and recent work by Konow, both of which reveal pluralistic public conceptions of justice with the activation and weighting of particular principles of justice dependent on the salience of background distributive conditions, ${ }^{24}$ we entered the project dubious about the empirical accuracy of theoretical views that place all of the emphasis

\footnotetext{
${ }^{23}$ See Norman J. Finkel, Commonsense Justice 319 (1995); PAul H. Robinson \& John M. Darley, Justice, LIABILITY \& BLAME 213 (1995).

${ }^{24}$ See James Konow, Which Is the Fairest One of All? A Positive Analysis of Justice Theories, 41 J. ECON. LIT. 1188, (2003); Gregory Mitchell et al., Judgments of Social Justice: Compromises Between Equality and Efficiency, 65 J. Personality \& Social Psychol. 629, 637 (1993) [hereinafter Mitchell et al., Compromises]; Gregory Mitchell et al., Experiments Behind the Veil: Structural Influences on Judgments of Social Justice, 24 POL. PsychOL. 519, 540 (2003) [hereinafter Mitchell et al., Experiments Behind the Veil].
} 
on background distributive conditions (the strong distributive priority view) or none of the emphasis on these background conditions (the independence view). Instead, we predicted that people would see both corrective and distributive justice as valid concerns to be harmonized when possible, with neither having a consistent trump value. Furthermore, the perfectionism of a strong distributive priority view makes it a priori untenable from an empirical standpoint: in its most unique and defensible normative form, the distributive priority view implies that there must be perfect distributive justice for corrective justice to take hold but existing tort systems in imperfect societies arguably instantiate forms of corrective justice (i.e., a strong distributive priority view treats corrective justice as equally inapplicable in grossly imperfect and slightly imperfect worlds; a weak distributive priority view resembles a form of the interdependence view).

Therefore, we predicted that if corrective justice is one of the principles of justice that possesses moral force in the public mind, then something more in line with a weak distributive priority or interdependence view of corrective justice is likely to accord with public conceptions of the relationship between distributive and corrective justice, with corrective justice giving way under clearly unjust distributive conditions but retaining normative force in moderately and perfectly just distributive settings. The independence view, in contrast, predicts strong support for the norm of corrective justice across all background distributive conditions.

\section{Overview of the Experimental Design and Summary of the Empirical Tests}

Our experiments employed a "hypothetical societies" paradigm, which is an impartial reasoning device that makes special use of the vignette approach to obtaining justice 
judgments. ${ }^{25}$ Whereas vignette studies typically ask participants to judge whether justice occurred in some realistic but imaginary event (e.g., pay distribution in a hypothetical work setting), the hypothetical societies approach asks participants to assume the perspective of an outside observer to imaginary societies and to evaluate the justice of events occurring within those societies. ${ }^{26}$ This approach is particularly useful in examining societal-level distributive justice, or social justice, because it permits the manipulation of both macro- and micro-level variables within vignettes. In essence, we ask participants to reason through a set of controlled thought experiments in which different features of the hypothetical societies systematically vary to see how these variables affect judgments of justice, if at all.

In our first experiment, we examined whether support for the corrective justice norm varied with the type of tort committed (intentional versus unintentional), the relative wealth of the victim and tortfeasor, and the degree of distributive justice in the society. The vignettes presented wrongful harms that should trigger a norm of corrective justice, all things being equal, under any corrective justice theory: each scenario involved a human agent who directly caused economic harm to another in circumstances indicating no consent to the harm and under circumstances in which the harm was foreseeable or within the actor's control. We expressly specified that the tortfeasor acted negligently or intentionally to avoid interpretive differences among participants about the tortfeasor's mental state or level of wrongdoing. The main task for

\footnotetext{
${ }^{25}$ We first developed this hypothetical societies paradigm for the research reported in Mitchell et al., Compromises, supra note 24. The paradigm has now been used by other researchers as well. See, e.g., John T. Scott et al., Just Deserts: An Experimental Study of Distributive Justice Norms, 45 AM. J. POL. ScI. 749, 765 App. (2001).

${ }^{26}$ The hypothetical societies approach divorces participants from the interests of the affected parties to avoid common egocentric biases found in judgments of justice rendered by interested parties. See generally Nicholas Epley \& Eugene M. Caruso, Egocentric Ethics, 17 SoC. JustiCE RES. 171, 172 (2004). This method approximates a Rawlsian "veil of ignorance," JOHN RAWLS, THEORY OF JUSTICE 136 (1971), which is the best we can do because we can not divest participants of the self-knowledge required by a true veil of ignorance.
} 
participants was to decide whether the person causing the loss should compensate the person who suffered the loss, as corrective justice would require.

Following Coleman’s explication of the “core” of corrective justice, the scenarios contained the three central elements of any theory of corrective justice: (1) a loss resulting from human agency (2) that is the basis for a claim of repair or rectification (3) between correlative persons (i.e., between persons in a relationship in which one bears causal or other responsibility for the loss suffered by the other). ${ }^{27}$ Thus, the scenarios should satisfy the view that both wrongful conduct and a wrongful loss have occurred under circumstances that make the injurer outcome-responsible or fairly charged with the tortious act. By varying the type of tort and the relative economic status of the correlative parties, we were able to test the generality of support for, or opposition to, the corrective justice norm (e.g., will the independence view hold only with respect to intentional torts, and will the distributive priority view hold even when a deservedly poor person negligently harms a deservedly wealthy person?).

The first experiment operationalized distributive justice in the common sense in which Americans deem possessions to be justly held and inequalities of wealth to be justified, namely, when the socioeconomic ordering is based on individual economic desert. ${ }^{28}$ People who

\footnotetext{
${ }^{27}$ See Coleman, supra note 16, at 66. The tort scenarios used in all three experiments reported here are reproduced in a Methodological Appendix to this article available from the authors or available online at http://www.blackwellpublishing.com/journal.asp?ref=1740-1453\&site=1.

${ }^{28}$ See, e.g., MiLLER, supra note 22, at 131; Neil D. Christiansen \& Howard Lavine, Need-efficiency Trade-offs in the Allocation of Resources: Ideological and Attributional Differences in Public Aid Decision Making, 10 SOC. JUsTICE RES. 289 (1997); Noah Lewin-Epstein, Amit Kaplan \& Asaf Levenon, Distributive Justice and Attitudes Toward the Welfare State, 16 Soc. Justice RES. 1, 4 (2003); Sidney Verba \& Gary R. Orren, The Meaning of Equality in America, 100 PoL. SCI. Q. 369, 374 (1985). This is not to say that all individuals equally support the view that merit-based distributions justify inequalities or the disregard of needs. For instance, Scott and his colleagues found that support for the principle of merit differed by gender and, among men, by political ideology. See Scott et al., supra note 25, at 763. Support for the merit principle is particularly strong, however, with respect to earnings. See Charles E. Mueller \& Tor Wynn, The Degree to Which Justice Is Valued in the Workplace, 13 Soc. Justice Res. 1, 17 (2000). To ensure that participants perceived the distributive justice manipulations as intended, we employed manipulation checks in Experiments 2 and 3, and these checks confirmed that participants viewed the hypothetical societies as varying in their levels of distributive justice.
} 
subscribe to a meritocracy-based view of distributive justice accept economic inequalities so long as the inequalities arise from allocations proportional to differential effort, assuming relative equality of opportunity. ${ }^{29}$ The meritocracy conception of distributive justice in a sense parallels the corrective justice concept: individuals who produce goods through their own efforts should reap the benefits of those efforts just as an individual whose efforts produce harm should bear the burdens of those efforts. Therefore, when we experimentally negate the distributive relation between effort and outcomes, will moral observers negate the corrective relation between actions and outcomes?

We created three societies varying in degree of meritocracy: (1) in Society Zero individual effort and ability played no role in determining socioeconomic status (the no meritocracy condition); (2) in Society Half individual effort and ability were moderate predictors of outcomes, determining socioeconomic status $50 \%$ of the time (the moderate meritocracy condition); (3) in Society One Hundred the relationship between merit and outcome was perfect, meaning that those who chose to work hard always prospered (the perfect meritocracy condition). By situating the hypothetical torts within these different societies, we were able to assess the relationship between distributive and corrective justice. ${ }^{30}$

\footnotetext{
${ }^{29}$ We have found meritocracy to be an important mediating factor in the judgments of distributive justice made by both liberals and conservatives. In our prior research, level of meritocracy mediated tolerance of economic inequality regardless of where a subject's views fell along the political spectrum, with tolerance of economic inequality increasing as the relationship between individual effort and economic outcomes became more reliable within a society. Thus, radical liberals will rate inegalitarian distributions as just in the presence of meritocracy, while staunch conservatives will rate egalitarian distributions as just in the absence of meritocracy. See generally Mitchell et al., Compromises, supra note 24; Mitchell et al., Behind the Veil, supra note 24.

${ }^{30}$ Because some persons subscribe to a needs-based view of distributive justice, we placed our hypothetical poor tortfeasor below the poverty line. This allowed us also to check for the priority of satisfying needs over doing corrective justice (i.e., participants who felt that need trumped corrective justice would not impose on the poor tortfeasor a duty to correct the loss). Also, because some persons believe distributive justice requires equality, we varied the relative wealth of the tortfeasor and victim, which allowed us to test whether an equality-based view of distributive justice trumped corrective justice (i.e., participants who felt equality trumped corrective justice would also not impose a compensation duty on the poor tortfeasor).
} 
Using these experimental manipulations, we formulated the following empirical tests of

the competing theoretical positions on the relation between corrective and distributive justice:

1. The Independence view: participants should impose on the tortfeasor a duty to compensate across all conditions in all three experiments (i.e., we should find no effects for any of the independent variables, with participants uniformly requiring the tortfeasor to compensate the victim).

2. The Distributive Justice Priority view: participants should impose on the tortfeasor a duty to compensate in the perfectly just society regardless of type of tort or identity of the tortfeasor but not in the moderately and fully unjust societies (i.e., we should find a main effect for the distributive justice independent variable, with the number of participants imposing a compensation duty in the just society being significantly greater than the number doing so in the moderately and fully unjust societies).

3. The Interdependence view: participants should impose a duty to compensate in the just and moderately just societies but not in the fully unjust society (i.e., we should find a main effect only for the distributive justice independent variable, but a significantly greater number of participants should impose a compensation duty in both the just and moderately just societies relative to the fully unjust society).

\section{Experiment 1: Meritocracy, Private Insurance, and Corrective Justice}

\section{A. Method}

Experiment 1 employed a 3 (level of meritocracy: none, moderate and perfect) X 2 (type of tort: intentional and unintentional) X 2 (relative wealth of victim: wealthy harmed by poor versus poor harmed by wealthy) within-subjects full factorial design. Accordingly, participants read twelve vignettes representing all combinations of the three independent variables, and after each vignette participants answered a series of questions, the responses to which constituted the dependent measures. For this initial experiment, we employed a within-subjects design to conduct a stringent test of the strength of the corrective justice norm in the face of salient shifts in background distributive conditions. Because each participant was exposed to all levels of the independent variables, the changes in these variables became quite salient and participants could perceive a demand to alter their responses as the independent variables changed. Therefore, 
consistent application of the corrective justice norm in the face of these implicit demands to respond differently would evidence strong support for the corrective justice norm. We controlled for order effects in the presentation of vignettes by following Keppel's procedure for constructing a "diagram-balanced" design, which ensured that each vignette occurred equally often in the sequence and that all vignettes both preceded and followed one another. ${ }^{31}$

\section{Participants}

Thirty-six students at the Florida State University College of Law volunteered to participate in the study, and each volunteer received a \$10 payment. Twenty-nine of the participants were first-year law students, and seven were second-year law students, with the sample having a mean age of 25.58 and a median age of 24. Twenty-one males and 15 females participated. The participants were predominantly White, with 29 participants self-identifying as White, two as Black, two as Hispanic, and three as Asian. With respect to political affiliations, 13 participants self-identified as Republicans, 14 as Democrats, and 9 as Independents.

Responses to two additional political attitudes questions confirmed the range of political views within our sample: the mean score on a seven-point scale ranging from "very liberal" (1) to "moderate" (4) to "very conservative" (7), was $4.25(S D=1.85)$, and the mean score on a sevenpoint scale asking participants whether they tended to agree more with Republicans (1), each party equally (4), or Democrats (7), was $4.00(S D=2.91)$.

Procedure and Materials

Individuals participated in the experiment in small group sessions. On arrival at an experimental session, each participant completed an informed consent form and then received an

\footnotetext{
${ }^{31}$ See Geoffrey Keppel, Design \& AnAlysis: A Researcher’s HandBoOK 377 (2d ed., 1982). Tests for order effects on the main dependent variable (whether, as a matter of justice, the tortfeasor should be made to compensate the victim ) in each of the experiments found no influence for order of scenario presentation.
} 
experimental packet containing (1) questions about demographics and other participant background information, (2) the main experimental task involving the hypothetical society vignettes, and (3) concluding questions that asked participants to reflect on their judgment strategy and to compare the hypothetical societies to the United States. All responses were anonymous. After completing the experimental packet, participants were debriefed and given an opportunity to ask questions about the study.

Before judging the vignettes that comprised the experimental manipulations, each participant provided information about his/her age, sex, race, income, and year in law school. Participants also rated their political views on a seven-point scale ranging from very liberal to very conservative, rated their degree of agreement with Republicans versus Democrats on a seven-point scale, and were asked to label themselves as Republican, Democrat, or Independent.

After completing these introductory questions, participants read about the "Ideal Societies Assessment Project," which described participants’ main judgment task and encouraged them to approach the task with an impartial, deliberative mindset. Participants then evaluated twelve vignettes created by a combination of the three independent variables.

With respect to the specific content of the vignettes, participants first read a description of a society that emphasized the relationship between effort and economic outcomes within the society, and thus which served to operationalize the level-of-meritocracy independent variable, as described above (Society Zero = no meritocracy; Society Half = moderate meritocracy; Society One Hundred $=$ perfect meritocracy). Following the society description, participants were introduced to Jim Smith, a very wealthy man living in the society, and John Dover, a very poor man living in the society. The relationship between each person's merit and socioeconomic standing within the particular society was made explicit (e.g., in Society One 
Hundred, it was emphasized that Jim Smith was wealthy because of his hard work and that John Dover was poor due to his lack of effort and initiative). Participants then read a short description of a tort that had occurred within the society involving Messrs. Smith and Dover.

The type-of-tort independent variable was operationalized as follows: for the intentional tort, participants read that either John Dover or Jim Smith had taken an expensive watch known to belong to the other person and pawned the watch for $\$ 1,000$ (i.e., each committed the tort of conversion); for the unintentional tort, participants read that John Dover, a groundskeeper, had negligently left a sprinkler system running on John Smith’s property, causing \$1,000 worth of damage to Smith’s home, and read that Jim Smith had negligently driven into John Dover's riding lawnmower, causing $\$ 1,000$ worth of damage (i.e., each committed an act of negligence of the same objective severity). The relative-wealth-of-the-victim independent variable was thus operationalized by telling participants either that Jim Smith, the extremely wealthy man, had been harmed by John Dover, the extremely poor man, or vice versa.

Following each vignette, participants answered the following question: "As a matter of justice rather than law, should [John Dover/Jim Smith] be made to compensate [Jim Smith/John Dover] under these circumstances?” Responses to this yes/no question about the tortfeasor's ethical duty to compensate the victim comprised the primary dependent variable measurement. In addition, after each vignette participants rated on seven-point scales the wrongfulness of actions of the tortfeasor, the amount of harm suffered by the victim, the degree to which the tortfeasor deserved punishment, and the likely deterrent effect of forcing the tortfeasor to compensate the victim. Finally, for each vignette the participant was asked to assume that the victim had private insurance that would cover the loss in question and asked to decide whether such insurance coverage would change their judgment about what justice requires in this case 
with respect to compensation (here participants chose between the following options: "Yes, I would change my answer if insurance covered the damage/loss" and "No, my answer would remain the same even if insurance covered the damage/loss").

After evaluating all twelve vignettes, participants identified which hypothetical society (Zero, Half, or One Hundred) they believed to be most similar to American society, and rated, on seven-point scales, their degree of support for a move to a nation-wide system of no-fault liability funded by the government and for a move to a nationwide-system of health insurance funded by the government.

\section{B. Results}

Main Dependent Variable: Should the Tortfeasor Compensate the Victim?

A majority of participants expressed the view that the tortfeasor should compensate the victim across all conditions of the experiment, but there was a significant drop in support for corrective justice when the tort was committed by the undeserving poor man against the undeserving rich man. As the solid line in Figure 1 reveals, only when the poor man committed an unintentional tort in Society Zero or Society Half did the percentage of participants endorsing a duty to compensate drop below $83 \%$, but even there a majority of participants felt the undeserving poor man should compensate the victim as a matter of justice (in Society Zero, 39\% judged that the poor man should not compensate the rich man for the act of negligence and 25\% refrained from imposing a compensation duty on the poor man for his negligence in Society Half). A Cochran test confirmed that these differences in the percentage of participants holding the tortfeasor morally liable across conditions were not likely due to chance variation, Cochran's $Q$ (with 11 degrees of freedom $)=57.60, p<.01$. 
Insert Figure 1 about here

Although Figure 1 makes clear that most participants made judgments in line with the independence view of corrective justice, the strongest prediction drawn from the independence view was that the distributive justice manipulation would have no significant effect on judgments. To test this strong prediction, we conducted a logistic regression to examine whether the distributive justice independent variable exerted a main effect on participants’ judgments about whether justice required compensation by the tortfeasor and, if so, the function that the effect took. The meritocracy variable did significantly influence participants' compensation judgments, Wald's statistic with 2 degrees of freedom $(W(2))=18.13, p<.01$, with the contrast between Society Zero and Society One Hundred being significant, $(\beta)=1.62($ S.E. $=.43), W(1)=$ 14.42, $p<.01, \exp (\beta)=5.04$, but the contrast between Society Half and Society One Hundred was not significant, $\beta=.54($ S.E. $=.47), W(1)=1.30, p=.25, \exp (\beta)=1.72$. Therefore, while a majority of participants made judgments in line with the independence view of corrective justice, the strongest prediction drawn from the independence view failed for a significant minority of the participants. For this minority, the interdependence view fared better than the distributive justice priority view, because the moderately just and fully just societies had similar effects on corrective justice judgments (i.e., moderate rather than full distributive justice was sufficient to trigger the imposition of a compensation duty).

We next conducted a stepwise regression adding interaction terms to the equation to determine whether the effects of the hypothetical society variable differed depending on the type of tort or identity of the victim. ${ }^{32}$ The final model included the main effect for meritocracy, $W$

\footnotetext{
${ }^{32}$ It is important to test for effects of the latter variable in particular to determine whether a needs-based conception
} of distributive justice took priority over corrective justice. For this and subsequent stepwise regressions that we 
$(2)=11.18, p<.01$, with the contrast between Society Zero and Society One Hundred significant, $\beta=1.156$ (S.E. $=.45$ ), $W(1)=6.61, p=.01, \exp (\beta)=3.18$, but the contrast between Society Half and Society One Hundred not significant, $\beta=-.43$ (S.E. $=.63$ ), $W(1)=.46, p=.50$, $\exp (\beta)=.65$. This model also included a three-way interaction among the meritocracy, tort type, and victim identity independent variables, $W(2)=19.48, p<.01$. We conducted a series of focused nonparametric tests to clarify the effects of the interaction of experimental manipulations on compensation judgments.

First, significant variation in response patterns occurred only with respect to the tort committed by the poor man, as a Cochran test of only those conditions in which the rich man committed a tort against the poor man revealed only a marginally significant difference in response frequencies, Cochran's $Q(5)=10.00, p=.08$. Therefore, while there was some variation in responses depending on level of meritocracy and type of tort, most respondents felt it proper to impose a duty of compensation on the rich man for his tortious acts across all conditions.

Looking more specifically at responses toward the poor man’s actions, first with respect to Society One Hundred, respondents did not differ significantly in the frequency with which they felt the poor man's torts gave rise to a duty of compensation, with McNemar's test of the cross-tabulation of responses yielding $p=.13$ (for all McNemar's tests in Experiment 1, $N=36$ ).

report, we employed a forward inclusion method with entry testing based on the significance of the score statistic and removal testing based on the probability of a likelihood-ratio statistic based on the maximum partial likelihood estimates. We employed a stepwise procedure rather than a block entry of all variables because of the small sample size and risk of inflated standard error estimates from inclusion of irrelevant variables in such an omnibus model. For discussion of stepwise logistic regression and its use to identify interaction effects, see JAMES JACCARD, INTERACTION EFFECTS IN LOGISTIC REgRESSION 15-17, 63-65 (2001); SCOTT MENARD, APPLIED LOGISTIC REgRESSION ANALYSIS 54-57 (1995); see also Robert B. Bendel \& A.A. Afifi, Comparison of Stopping Rules in Forward "Stepwise" Regression, 72 J. AM. STAT. Ass'N 46 (1977). We report results from regressions using $p=$ .05 for entry into and $p=.10$ for removal from the model. Per Menard's (1995) recommendation, we also ran regressions using the more lenient entry and removal statistic of $p=.15$, which yielded almost identical models in all three experiments. Statistics for these alternative models, and all other unreported statistics, are available on request. 
However, in Societies Zero and Half significantly fewer participants imposed a duty of compensation for the act of negligence than for the act of conversion, with McNemar's tests yielding $p=.02$ and $p=.01$, respectively. Considering responses to the two torts across the three societies, we found that only two of the conditions differed significantly in their response frequencies: regardless of type of tort, significantly fewer respondents imposed a duty to compensate on the poor man in Society Zero as compared to Society One Hundred, with McNemar's tests yielding $p<.01$ for the negligence comparison and $p=.03$ for the conversion comparison.

Thus, as suggested in Figure 1, when an intentional or unintentional tort was committed by a rich man or took place in the just society (Society One Hundred), participants almost uniformly judged the tortfeasor to have a duty to compensate the victim. However, when the society was perfectly unjust (Society Zero), a significant number of participants changed their responses and did not impose a duty to compensate on the poor man for either the intentional or unintentional tort. Furthermore, in both the perfectly unjust society and moderately unjust society (Society Half), a significant number of participants were less willing to impose a duty to compensate for the unintentional tort as compared to the intentional tort. Overall, we see a strong baseline tendency to impose a duty of compensation regardless of background distributive conditions, but we see a significantly greater tendency to impose this duty as the society moves closer to distributive justice and the upward slope is steeper for intentional than unintentional torts.

\section{Compensation Judgments in the Presence of Private Insurance}

It is possible that concern about the misfortune of the victim, rather than application of a norm of corrective justice, drove the participants to impose a duty of compensation on the 
tortfeasor. That is, absent some other means of compensating for the harm done, respondents may have felt that justice required that the loss be imposed on the person who caused the harm, the tortfeasor. Such a motive would arguably be more consistent with a local distributive justice concern than with the view that corrective justice requires the tortfeasor to restore equilibrium with his victim. To examine this possibility, we asked participants whether private insurance coverage for the loss would affect their judgments about whether the tortfeasor should compensate the victim.

The dashed line in Figure 1 represents the percentage of respondents who imposed a compensation duty on the tortfeasor despite the victim's having private insurance coverage for the loss in question. Comparisons of compensation judgments made without regard to private insurance and made in the presence of private insurance revealed that a significant number of participants altered their responses in three of the experimental conditions: (1) in the case of the poor man who negligently harmed the rich man in Society Half, 12 participants who originally imposed a compensation duty stated that they would not impose a compensation duty if private insurance covered the loss, while three participants who originally did not impose a compensation duty stated that they would impose a compensation duty if private insurance covered the loss (McNemar's test yielding a $p=.04)$; (2) in the case of the poor man who negligently harmed the rich man in Society One Hundred, nine participants who originally imposed a compensation duty stated that they would not impose a compensation duty if private insurance covered the loss, while one participant who originally did not impose a compensation duty stated that he would impose a compensation duty if private insurance covered the loss (McNemar's test yielding a $p=.02$ ); (3) in the case of the rich man who negligently harmed the poor man in Society Half, 11 participants who originally imposed a duty to compensate stated 
that they would not impose a compensation duty if private insurance covered the loss, while two participants who originally did not impose a compensation duty reported that they would impose a compensation duty if private insurance covered the loss (McNemar's test yielding a $p=.02$ ).

Therefore, while the existence of private insurance did not lead to wholesale changes in response patterns, suggesting that corrective justice did generally drive the original compensation judgments, the presence of insurance did cause a significant number of participants to be less strict in their enforcement of the corrective justice norm under some limited circumstances. In particular, acts of negligence committed by the poor man were excused at greater rates in the moderately and perfectly just societies (Societies Half and One Hundred, respectively). The lack of a significant difference in compensation judgments for the poor man's negligence in Society Zero likely reflects a baseline effect: the injustice of the society had already led those sensitive to background distributive conditions to excuse his act of negligence. Interestingly, the act of negligence by the rich man in Society Half also led to a significant reduction in the frequency with which a compensation duty was imposed on him, perhaps reflecting the ambiguity of distributive justice within Society Half: concern about taking wealth from the rich man to compensate the poor man should have been least in Society Zero, where the rich man's holdings were unearned, and concern about restoring the wealth of the poor man should have been least in Society One Hundred, where the poor man had shown no initiative and perhaps could be expected to squander the compensation.

Other Dependent Variables: Wrongfulness, Blame, Punishment, and Deterrence We examined the other dependent measures to gain insight into whether participants’ compensation judgments were motivated by justice concerns or were intended to serve another function, such as deterrence. First, we examined the impact of the independent variables on 
participants' ratings on these other dependent variables. Table 1 reports the results of analyses of variance for each of these dependent variables.

Insert Table 1 about here

The level-of-meritocracy and wealth-of-victim variables jointly influenced participants’ ratings of the degree of harm suffered by the victim (scored on 1 to 7 scale, with $1=$ "tremendous harm" and $7=$ "no harm at all). When the victim was wealthy, mean ratings of harm remained near the "moderate harm" center of the scale in all societies (Society Zero $M=$ 4.82; Society Half $M=4.67$; Society One Hundred $M=4.32$ ), but participants perceived the harm to the poor victim to be much greater in the perfectly unjust society than in the other societies (Society Zero $M=2.97$; Society Half $M=4.31$; Society One Hundred $M=5.11$ ).

The type-of-tort and wealth-of-victim variables also jointly influenced participants' ratings of how wrongful the actions of the tortfeasor were (scored on a 1 to 7 scale, with $1=$ "not wrongful at all” and 7 = "tremendously wrongful”). Participants rated the unintentional torts as less wrongful than the intentional torts, particularly so with respect to the act of negligence by the poor man (negligence by poor man $M=3.65$; conversion by poor man $M=5.81$; negligence by rich man $M=4.19$; conversion by rich $\operatorname{man} M=5.80$ ).

The level-of-meritocracy and wealth-of-victim variables also exerted an interactive effect on participants' ratings of how deserving of punishment the tortfeasor's acts were (scored on a 1 to 7 scale, with 1 = "very deserving of punishment" and 7 = "not deserving at all"). Whereas the rich man's actions were seen as approximately equally deserving of punishment in all societies (Society Zero $M=3.14$; Society Half $M=3.07$; Society One Hundred $M=3.04$ ), the poor man's 
actions were seen as more deserving of punishment as meritocracy increased (Society Zero $M=$ 3.79; Society Half $M=3.35$; Society One Hundred $M=2.83$ ).

Finally, the level-of-meritocracy and wealth-of-victim variables exerted main effects on participants' ratings of whether forcing the tortfeasor to compensate the victim would deter similar conduct by the tortfeasor in the future (scored on a 1 to 7 scale, with $1=$ "no deterrent at all” and 7 = "excellent deterrent”). In the perfectly unjust society forcing compensation was seen as a less effective deterrent than in the other societies (Society Zero $M=3.81$; Society Half $M=$ 4.48; Society One Hundred $M=4.58$ ), and forcing the poor man to compensate the rich man ( $M$ $=4.55)$ was seen as a more effective deterrent than forcing the rich to compensate the poor $(M=$ 4.02).

To determine whether these attitudes toward the harmfulness and wrongfulness of the acts, as well as attitudes about the need for punishment and the deterrent effect of forcing compensation, could explain the participants' judgments about the tortfeasor's duty to compensate the victim, ratings on these dependent measures were included as possible covariates in logistic regression analyses of the dichotomous judgment to impose a duty of compensation or not. In only two conditions did any of these covariates possess predictive power, which is not surprising given the high degree of agreement on compensation duties across experimental conditions. Attitudes about punishment and deterrence predicted judgments about the poor man's duty to compensate the rich man for the act of negligence committed in Society Zero: an increase in an act's perceived need for punishment made it significantly more likely that the participant would impose a compensation duty on the tortfeasor, $\beta=1.26($ S.E. $=.55), W(1)=$ $5.25, p=.02, \exp (\beta)=3.53$, and a decrease in the perceived effectiveness of compensation made it significantly less likely that the participant would impose a compensation duty on the 
tortfeasor, $\beta=-.93($ S.E. $=.40), W(1)=5.50, p=.02, \exp (\beta)=.40$. Also, attitudes about the wrongfulness of the act of negligence committed by the poor man in Society Half predicted compensation judgments in the presence of private insurance: the lower the judged wrongfulness of the act, the greater the likelihood that the participant would not impose a compensation duty in the presence of private insurance, $\beta=-1.53($ S.E. $=.53), W(1)=8.48, p<$ $.01, \exp (\beta)=.22$.

Notwithstanding the results in these two conditions, it appears that compensation judgments generally were not seen as an avenue to blame fulfillment or punishment. Indeed, even though the independent variables significantly affected participants' attitudes about the harmfulness and wrongfulness of the acts and the need to punish the acts, the frequency of judgments imposing a compensation duty remained remarkably high except under conditions of extreme distributive injustice. This finding is consistent with Coleman's view that corrective justice is an end in itself rather than an instrumental means to social control. ${ }^{33}$

When private insurance was not at issue, 19 (52.8\%) of the participants imposed a compensation duty on the tortfeasor across all conditions, and, when private insurance was available, 12 (33.3\%) of the participants still imposed a compensation duty across all conditions. Therefore, the compensation judgments of over half of the participants showed no sensitivity to distributive justice, and the compensation judgments of one-third of the participants showed no sensitivity to alternative means of compensation, behaviors that are consistent with the independence view of corrective justice. Of course, this means as well that approximately twothirds of the participants showed some sensitivity to distributive justice or alternative means of

\footnotetext{
${ }^{33}$ See Coleman, supra, note 16.
} 
compensation in their compensation judgments, behaviors that are consistent with the interdependence view of corrective justice.

\section{Individual Differences}

We found no correlation between answers to demographic and political attitude questions and individual counts of the numbers of times that a compensation duty was imposed in the absence and presence of private insurance (the more frequently a duty to compensate was imposed, the less sensitive a participant was to background distributive conditions). However, a composite of participants’ political agreement (tend to agree more with Democrats or Republicans) and political views (tend to hold liberal versus conservative views) scores significantly predicted compensation judgments, with those scoring toward the conservative end of the scale more likely to impose a compensation judgment on the tortfeasor, $\beta=-.34$ (S.E. $=$ $.09), W(1)=14.55, p<.01, \exp (\beta)=.72$. In addition, this composite political ideology scale interacted with each of the independent variables: with meritocracy, $W(2)=11.86, p<.01$, with a significant contrast between Societies Zero and Hundred only, $\beta=.18$ (S.E. $=.06), W(1)=$ $10.13, p<.01, \exp (\beta)=1.19$; with type of tort, $\beta=14($ S.E. $=.04), W(1)=10.06, p<.01, \exp (\beta)$ $=1.15$; with wealth of victim, $\beta=.11($ S.E. $=.04), W(1)=6.81, p<.01, \exp (\beta)=.27$. If we examine participants’ compensation judgments by self-identified status as a Democrat, Republican, or Independent, we see that Democrats imposed a compensation duty less frequently than Republicans and Independents in Society Zero (69\% v. 84\% v. 83\%, respectively), but at about the same rates in Societies Half (90\% v. $88 \%$ v. 97\%) and One Hundred (94\% v. 93\% v. 97\%). And we see that Democrats were less likely to impose a compensation duty for negligence (77\% v. 83\% v. 89\%), but about as likely as Republicans and less likely than Independents to impose a compensation duty for conversion (92\% v. 93\% v. 96\%). 
Interestingly, with respect to the wealth of the victim, Independents differ more than Democrats and Republicans, imposing a compensation duty more frequently for both victims, but especially the rich victim (94\% v. 86\% v. 93\%, respectively, for the poor victim, and 91\% v. 81\% v. 83\% for the rich victim).

\section{Experiment Two: Racial Injustice and Corrective Justice}

The independence view of corrective justice found considerable support in Experiment 1's strong test of this theoretical position. We designed Experiment 2 with an eye towards constructing an even stronger test of the independence of corrective justice from distributive justice. Specifically, we retained the within-subjects design, which makes the distributive justice manipulation salient, and we made the distributive justice manipulation more graphic by making the poor man a member of a terribly oppressed race and the rich man a member of the oppressor race in one of the hypothetical societies (in "Society Blue," the racially-segregated caste society, the Blue race exerted racial dominance over the Purple race and ensured that members of the Purple race would remain impoverished; in Society Beige the Blue and Purple races were minority races within a moderately discriminatory society in which the Orange race was the more dominant majority, but members of these minority races could improve their status somewhat through hard work; in Society Rainbow all races were treated equally and hard work rather than race was the best predictor of socioeconomic status). Also, to simplify the design and focus attention on the poor man as tortfeasor, we held the tortfeasor-victim relationship constant in Experiment 2. Accordingly, Experiment 2 employed a 3 (level of meritocracy: none, moderate and perfect) X 2 (type of tort: intentional and unintentional) within-subjects full factorial design.

\section{A. Method}




\section{Participants}

Twenty-four first-year students at the Florida State University College of Law volunteered to participate in the study, and each volunteer received a \$10 payment. Eleven males and 13 females participated, with a mean age of 24.75 and a median age of 23 . As in Experiment 1, the participants were predominantly White, with 21 participants self-identifying as White, two as Hispanic, and one unspecified. With respect to political affiliations, nine participants self-identified as Republicans, ten as Democrats, and five as Independents. The mean score on the question asking participants to label their views from very liberal (1) to very conservative $(7)$ was $3.88(S D=1.45)$, and the mean score on the question asking participants whether they tend to agree more with Republicans (1) or Democrats (7) was $4.54(S D=1.88)$, together indicating a slight skew leftward in our sample.

\section{Procedure and Materials}

The procedure was identical to that used in Experiment 1, and the materials were identical to those used in Experiment 1 except in two respects. First, the content of the vignettes was altered to reflect modifications to the meritocracy variable and the deletion of the wealth-ofthe-victim variable. As in Experiment 1, the meritocracy manipulation contained three levels (no relation, a moderate relation or a perfect relation between economic outcomes and merit), but a racial discrimination explanation was given for the disjunction between outcomes and merit at the first two levels of the variable. In Society Blue, the no meritocracy society, race rather than individual merit was described as the sole determinant of economic outcomes, and in Society Beige, the moderate meritocracy society, participants were told that minorities did face some racial discrimination but that individual merit determined economic outcomes half of the time. In Society Rainbow, the perfect meritocracy society, individual merit solely determined 
economic outcomes for members of all races. After reading these revised societal descriptions, participants read about Jim Blue, a rich man, and John Purple, a poor man who was a groundskeeper at one of Jim Blue's homes. In Society Blue, Jim Blue was a member of the oppressor race, and John Purple was a member of the oppressed race. In half of the vignettes John Purple committed an act of negligence that caused $\$ 1,000$ in water damage to Jim Blue’s home, and in the other half John Purple intentionally converted a watch owned by Jim Blue worth $\$ 1,000$. As in Experiment 1, we controlled for order effects by constructing a diagrambalanced design.

Second, we added questions asking participants to rate the social justice of the three hypothetical societies on a separate seven-point scale (with $1=$ "extremely unjust" and 7 = "extremely just”). These three questions, which were added to the end of the experimental packet, served as manipulation checks on our operationalization of distributive justice as meritocracy.

\section{B. Results}

\section{Distributive Justice Manipulation Check}

Participants rated Society Blue $(M=6.71(S D=.46))$ to be significantly less just than both Society Beige $(M=4.46(S D=.88))$, paired-samples $t(23)=12.29, p<.01$, and Society Rainbow $(M=1.17(S D=.38))$, paired-samples $t(23)=34.85, p<.01$. Participants also rated Society Beige to be significantly less just than Society Rainbow, ( $M=4.46$ vs. $M=1.17)$, paired-samples $t(23)=15.48, p<.01$. Therefore, participants perceived the hypothetical societies as intended with respect to their relative degrees of distributive justice, with Society Blue being the most unjust, Society Beige moderately unjust but more just than Society Blue, and Society Rainbow being the most just. 


\section{Main Dependent Variable: Should the Tortfeasor Compensate the Victim?}

The solid line in Figure 2 presents the percentage of participants imposing a duty of compensation on the tortfeasor across the six conditions in the Experiment 2 without regard to the victim's insurance. A Cochran test of all conditions together confirmed that the frequency of judgments imposing a compensation duty varied significantly across the conditions, Cochran's $Q$ (5) $=43.20, p<.01$.

Insert Figure 2 about here

Holding the type of tort constant, Cochran tests indicated that compensation judgments about both the intentional and unintentional tort varied significantly across meritocracy conditions (for the conversion vignettes, Cochran's $Q(2)=16.22, p<.01$; for the negligence vignettes, Cochran's $Q(2)=17.71, p<.01)$. Logistic regression confirmed that the meritocracy manipulation exerted a main effect on compensation judgments, with a compensation duty being imposed more often outside the fully unjust society (overall $W(2)=24.43, p<.01$; contrast between Society Rainbow and Society Blue: $\beta=2.68$ (S.E. $=.61$ ), $W(1)=19.22, p<.01, \exp (\beta)$ $=14.51$; contrast between Society Rainbow and Society Beige: $\beta=.58$ (S.E. $=.63$ ), $W(1)=.85$, $p=.36, \exp (\beta)=1.79)$.

The type of tort variable also exerted a main effect on compensation judgments, $\beta=1.85$ $($ S.E. $=.50), W(1)=13.83, p<.01, \exp (\beta)=6.39$. Holding the level of meritocracy constant, McNemar comparisons of compensation judgments for the acts of negligence and conversion indicated that the type of tort variable significantly affected compensation judgments for Society Blue, where there was no meritocracy (with McNemar test yielding $p=.02$ ), and for Society 
Beige, where there was moderate meritocracy (Beige, with McNemar test yielding $p=.03$ ), but not for Society Rainbow, where there was perfect meritocracy, though the difference between the torts there did approach significance (with McNemar test yielding $p=.06$ ). Thus, participants were least likely to impose a compensation duty with respect to unintentional torts in a distributively unjust society. ${ }^{34}$

\section{Compensation Judgments in the Presence of Private Insurance}

The dashed line in Figure 2 presents the percentage of respondents who imposed a compensation duty on the tortfeasor in each condition despite the victim's having private insurance coverage for the loss in question. Comparisons of the compensation judgments made with and without regard to private insurance revealed only one condition in which a significant number of participants differed in their judgments: in Society Beige, eight participants who originally imposed a compensation duty did not do so when private insurance covered the loss from negligence, while one participant who originally did not impose a compensation duty did so when private insurance covered the loss (with McNemar's test yielding a $p=.04$ ). This result mirrors one of the effects of adding insurance in Experiment 1, where the presence of insurance also caused a significant change in compensation judgments with respect to the poor man's act of negligence in Society Half, the moderate meritocracy society. The general pattern of results seen here also mirrors that seen in Experiment 1: adding insurance coverage only slightly moderated the tendency to impose a compensation duty on the tortfeasor, suggesting that corrective justice rather than lack of alternative means of loss compensation motivated compensation judgments.

Other Dependent Variables: Wrongfulness, Blame, Punishment, and Deterrence

\footnotetext{
34 Stepwise regression including main effect and interaction terms yielded a final model that included only the previously reported significant main effects for the meritocracy and type of tort variables.
} 
Table 2 reports the results of analyses of variance on the secondary dependent variables. Participants' rated the harm done by the tort in Society Blue to be significantly less than the harm done in Societies Beige and Rainbow ( $M=5.35$ vs. $M=4.58$ vs. $M=4.60)$. Participants rated the wrongfulness of both torts less severely in Society Blue than in the other societies (Society Blue: negligence $M=3.00$, conversion $M=4.67$; Society Beige: negligence $M=3.33$, conversion $M=5.41$; Society Rainbow: negligence $M=3.42$, conversion $M=5.83$ ). The levelof-meritocracy and type-of-tort variables exerted main effects on punishment ratings: the tortious act was seen as less deserving of punishment in Society Blue than in Societies Beige and Rainbow ( $M=4.79$ vs. $M=3.81$ vs. $M=3.56$ ), and the intentional tort was seen as meriting more punishment than the unintentional tort ( $M=3.31$ vs. $M=4.81$ ). Finally, participants viewed imposing a duty of compensation on the tortfeasor to be a less effective deterrent in Society Blue $(M=3.69)$ than in Society Beige $(M=4.42)$ and Society Rainbow $(M=4.52)$.

Insert Table 2 about here

To determine whether the attitudes reflected in these secondary dependent measures might explain the participants’ binary compensation judgments, scores on these dependent measures were included as possible covariates in logistic regression analyses on the compensation judgments made in the absence and presence of private insurance. Ratings on these secondary measures predicted only compensation judgments about the intentional tort occurring in Society Blue, the perfectly unjust society, and here only ratings of the need to punish the tortfeasor's actions unequivocally predicted judgments. As a participant's rating of the need to punish the intentional tort within Society Blue decreased, it became significantly 
more likely that the participant would not impose a compensation duty, whether insurance was present or $\operatorname{not}(\beta=2.18$ (S.E. $=.90), W(1)=5.83, p=.02, \exp (\beta)=8.84$ without insurance; $\beta=$ 1.57 (S.E. $=.75), W(1)=4.37, p=.04, \exp (\beta)=4.79$ with insurance). This vignette apparently presented a significant number of the participants with a morally ambiguous situation in which it was not clear whether corrective justice required compensation, with attitudes about the need to punish the wrongful behavior resolving this ambiguity.

\section{Individual Differences}

When private insurance was not at issue, six (25\%) of the participants imposed a compensation duty on the tortfeasor across all conditions, five (20.8\%) participants imposed a compensation duty in five of the six experimental conditions, and seven (29.2\%) participants imposed a compensation duty in four of the conditions. Thus, 18 (75\%) participants imposed a compensation duty more often than not. When private insurance was available, three (12.53\%) of the participants imposed a compensation duty across all conditions, two (8.3) in five conditions, and 8 (33.3\%) in four conditions, bringing the total participants who imposed a duty more often than not, despite insurance coverage, to 13 (54.2\%).

Given the greater variation in compensation judgments in Experiment 2 than in Experiment 1, it was not surprising to find some significant individual difference predictors of behavior that we did not find earlier. In particular, participants' self-placement on the liberalconservative scale correlated significantly with frequency of imposing a compensation duty absent insurance ( $r=.42, p=.04$ ), with conservatives imposing a compensation duty more frequently. Consistent with this finding, participants' ratings of how often they agree with the policies of the Republicans versus the Democrats also correlated significantly with compensation judgments in the absence of insurance $(r=-.47, p=.02)$, with persons who tend to agree more 
often with the policies of the Republicans imposing a compensation duty more frequently than those who agree more often with the Democrats. Also, persons who expressed greater support for a move to a national system of health care insurance imposed a compensation duty less frequently than those expressing less support for such a system, both with respect to compensation judgments made in the absence of private insurance $(r=-.44, p=.03)$ and compensation judgments made in the presence of private insurance $(r=-.71, p<.01)$. Interestingly, ratings on the question about national health care insurance were not significantly correlated with Republican-Democratic Party agreement $(r=.34, p=.11)$ but approached significance for liberal-conservative self-placement $(r=-.39, p=.06)$.

Consistent with these correlational results, logistic regression revealed a first-order interactions between meritocracy and scores on the composite measure of political ideology, $W$ $(2)=25.79, p<.01$, and type of tort and the political ideology composite, $W(1)=14.58, p<.01$. These interactions can be understood, and the effect of holding liberal political views can be vividly illustrated, by examining the ideological breakdown of compensation judgments made in Society Blue versus the other societies. None of the persons who self-identified as Democrats imposed a compensation duty on the tortfeasor for his negligence in Society Blue, whereas persons who self-identified as Republicans or Independents were about evenly split in their compensation judgments when insurance was not at issue. However, once an intentional tort occurred or distributive injustice became less extreme, Democrats exhibited a pattern of mixed judgments similar to that found within Republicans and Independents. Hence, as a group, Democrats found an unintentional tort that occurs in a racially unjust society a particularly bad candidate for application of the corrective justice norm—perhaps because Democrats find racial injustice particularly aversive or perhaps because Democrats are more susceptible to vivid 
evidence. While an impression management hypothesis is plausible (i.e., Democrats perhaps felt a great need to project a public image of opposition to racial oppression), it seems unlikely as an explanation given the anonymity of participants’ responses.

The susceptibility-to-vivid-evidence hypothesis may be worthy of pursuit, because, from a just deserts perspective, there is no principled reason to treat the abstract lack of meritocracy in the first experiment differently than the more vivid lack of meritocracy in the second experiment. From a psychological perspective, however, the finding of greater sensitivity to the racial dimension of distributive justice among liberals is consistent with other strands of evidence that racial political appeals carry a special charge for early $21^{\text {st }}$ century egalitarians. Prior work by one of the authors has shown that liberals were more sensitive to, and resistant to the use of, race-tainted base rate information than conservatives, with respect to the setting of insurance rates. In that study, liberals exhibited opposition to using the race-tainted base rate information on moral grounds that such use would further harm those already discriminated against, despite counter-arguments for the use of the base rate information, and the same sort of "moral cleansing” effect could have been going on with liberal participants in the present study. ${ }^{35}$

${ }^{35}$ See Philip E. Tetlock et al., The Psychology of the Unthinkable: Taboo Trade-Offs, Forbidden Base Rates, and Heretical Counterfactuals, 78 J. PersonAlity \& Soc. Psychol. 853, 863-64 (2000). There is also evidence that liberals are more likely than conservatives to support the use of military force abroad to stop ethnic cleansing but not to stop other forms of equally murderous aggression. See Richard Hermann et al., Mass Public Decisions on Going to War: A Cognitive-Interactionist Framework, 93 AMER. POL. SCI. ReV. 553 (1999).

As suggested by one of the reviewers, we conducted tests of the hypothesis that the meritocracy manipulation in the second experiment was perhaps more vivid and compelling than the meritocracy manipulation in the first experiment by combining the data from the two experiments and making experiment a between-subjects independent variable. Stepwise regression found a significant main effect for type of tort, $W(1)=26.05, p<.01$, a significant interaction between experiment and meritocracy level, $W(3)=14.27, p<.01$, and a significant interaction between meritocracy and political party agreement, $W(5)=38.40, p<.01$. Further examination of responses just to the negligent tort (for which there tended to be greater variation) revealed a pattern of results supportive of the vividness hypothesis: (1) significantly more participants imposed a compensation duty on the negligent tortfeasor in the no-meritocracy condition in Experiment 1 than in Experiment 2 (61\% in Society Zero v. $29 \%$ Society Blue), $W(1)=4.55, p=.03$, with none of the political identification measures being significant predictors; (2) with respect to responses in the moderate-meritocracy societies (Societies Half and Beige), the overall percentages did not differ significantly but persons holding more conservative views and more likely to 


\section{Experiment Three: Meritocracy, Social Insurance, and Corrective Justice}

\section{A. Method}

We conducted a third experiment with two purposes in mind: first, to attempt to replicate the finding from Experiment 1 that a majority of participants exhibited no concern for background distributive justice in their compensation judgments, and, second, to examine whether a government-funded alternative to tortfeasor compensation would affect participant support of the corrective justice norm. ${ }^{36}$ Accordingly, we utilized the more abstract meritocracy manipulation from Experiment 1, and we added a "social insurance" manipulation: in half of the conditions, participants read that the hypothetical society had recently instituted a taxpayerfunded no-fault liability insurance system that would compensate victims of torts after a brief investigation to verify claims, and in the other half there was no mention of such a fund. We retained the type-of-tort manipulation from Experiment 1, but, to keep the design manageable, we deleted the wealth-of-victim manipulation (i.e., in all conditions, the poor man harmed the rich man, as in Experiment 2). Also, in order to heighten the contrast in distributive justice between the hypothetical societies, we continued use of the within-subjects design but included

identify as conservatives were significantly more likely to impose a compensation duty on the negligent tortfeasor, $W(1)=5.29, p=.02$ and $W(1)=4.84, p=.03$, respectively; and (3) with respect to responses in the fullmeritocracy societies (Societies Hundred and Rainbow), the overall percentages did not differ significantly but persons holding more conservative views were significantly more likely to impose a compensation duty on the negligent tortfeasor than those holding more liberal views, $W(1)=4.73, p=.03$. Although these tests provide some evidence that liberals and conservatives reacted differently to the meritocracy manipulations, particularly when the effects of meritocracy were ambiguous, more focused examination of the interaction among forms of distributive justice, corrective justice, and political ideology is needed to determine whether ideology mediates the relation between distributive and corrective justice.

${ }^{36}$ The social insurance scheme employed in the third experiment was loosely based on New Zealand's no-fault accident compensation scheme. The New Zealand system is financed primarily by employer and employee taxes and covers a broad range of personal injuries (notwithstanding the term "accident" in the New Zealand Accident Compensation Commission's name, personal injuries covered include harms caused by criminal acts). See Bronwen Lichtenstein, From Principle to Parsimony: A Critical Analysis of New Zealand's No-Fault Accident Compensation Scheme, 12 SoC. JUSTICE RES. 99 (1999). We funded our hypothetical system through a progressive payroll tax and had it cover both intentional and unintentional torts (see the Methodological Appendix for the exact description given to participants). 
only Societies Zero and One Hundred. Therefore, Experiment 3 employed a 2 (level of meritocracy: none and perfect) X 2 (type of tort: negligence and conversion) X 2 (social insurance or no social insurance) within-subjects full factorial design, leading to the creation of eight vignettes for participants to evaluate.

\section{Participants}

Twenty-two students at the Florida State University College of Law volunteered to participate in the study, and each volunteer received a \$10 payment. Three first-year students, 16 second-year students, and three third-year students participated, nine of whom were male and 13 female. Participants had a mean age of 26.14 and a median age of 25. As in Experiments 1 and 2, the participants were predominantly White, with 18 participants self-identifying as White, three as Asian, and one as Hispanic. With respect to political affiliations, seven participants selfidentified as Republicans, nine as Democrats, and six as Independents. The mean score on the question asking participants to label their views from very liberal (1) to very conservative (7) was $3.91(S D=1.54)$, and the mean score on the question asking participants whether they tend to agree more with Republicans (1) or Democrats (7) was $4.23(S D=2.07)$.

\section{Procedure and Materials}

The procedure was identical to the procedure in Experiment 1, and the materials were identical to those used in Experiment 1 except in the following three respects. First, the moderate meritocracy (Society Half) manipulation was deleted from the meritocracy variable and the wealth-of-victim variable was deleted. In all of the vignettes, the poor man (John Dover) caused harm to the property of the rich man (Jim Smith), either through negligence or an intentional act of conversion. Second, we removed the questions about how private insurance would affect participants' original compensation judgments, but we added the social insurance 
variable mentioned above. Thus, for each society and each tort, participants made compensation judgments in the absence of a social insurance fund that could serve as an alternative means of compensation and in the presence of such a fund. (As in Experiments 1 and 2, we controlled for order effects by arranging vignettes in a diagram-balanced design.) Third, as in Experiment 2, we added to the end of the experimental packet questions that served as manipulation checks on the meritocracy variable.

\section{B. Results}

\section{Distributive Justice Manipulation Check}

Participants rated Society Zero $(M=5.95(S D=1.21))$ to be significantly less just than Society One Hundred $(M=2.45(S D=1.67))$, paired-samples $t(21)=6.56, p<.01$. Therefore, participants perceived the hypothetical societies as intended with respect to their respective levels of social justice.

\section{Main Dependent Variable: Should the Tortfeasor Compensate the Victim?}

Figure 3 presents the percentage of participants imposing a duty of compensation on the tortfeasor in the absence and presence of social insurance. A Cochran test of all conditions together confirmed that the frequency of judgments imposing a compensation duty varied significantly across the conditions, Cochran's $Q(7)=47.70, p<.01$. Logistic regression revealed main effects for both the meritocracy variable $(\beta=1.30($ S.E. $=.41), W(1)=9.94, p<$ $.01, \exp (\beta)=3.68)$ and the type of tort variable $(\beta=2.26$ (S.E. $=.49), W(1)=22.60, p<.01$, $\exp (\beta)=9.25)$, but revealed no main effect for the social insurance variable or significant interactions.

Insert Figure 3 about here 
Holding the type of tort and the presence/absence of social insurance constant, McNemar tests for significant differences in the frequency of compensation judgments between the levels of meritocracy found only one significant difference: participants imposed a compensation duty on the tortfeasor significantly more frequently for the act of negligence when it occurred in Society One Hundred than when it occurred in Society Zero (McNemar $p=.02)$, with seven of the 18 persons who imposed a compensation duty in Society Hundred imposing no such duty in Society Zero.

Holding the type of tort and level of meritocracy constant, McNemar tests revealed no significant differences in the frequency of compensation judgments in the presence and absence of the social insurance fund (i.e., adding the social insurance fund did not make participants less likely to refrain from imposing a compensation duty on the tortfeasor), though the difference for the act of negligence in Society One Hundred approached significance (with McNemar's test yielding $p=.06)$.

Holding the level of meritocracy and the presence/absence of social insurance constant, McNemar tests indicated significant differences in judgments about the two torts. In Society Zero, a compensation duty was imposed more frequently for the intentional tort than the unintentional tort whether social insurance was available or not (McNemar $p=.02$ for the negligence-conversion contrast in the absence of social insurance, with 7 persons switching their judgments, and McNemar $p<.01$ for the negligence-conversion contrast in the presence of social insurance, with 9 persons switching their judgments). In Society One Hundred, in the presence of the social insurance fund, participants were less likely to impose a compensation duty on the 
tortfeasor for his act of negligence than conversion (McNemar $p<.01$, with 9 persons switching from imposing a duty for conversion to no duty for negligence).

Other Dependent Variables: Wrongfulness, Blame, Punishment, and Deterrence

Table 3 reports the results of analyses of variance on the secondary dependent variables. None of the independent variables affected participants' ratings of the harmfulness of the poor man's actions; across all conditions participants rated the tortfeasor's actions as slightly more than moderately harmful (grand mean $=4.91$ ). With respect to ratings of how wrongful the tortfeasor's actions were, the meritocracy and type-of-tort variables exerted main effects: the actions were seen as more wrongful when committed in Society One Hundred than in Society Zero $(M=4.99$ vs. $M=4.43)$, and the intentional tort was seen as more wrongful than the unintentional tort $(M=5.93$ vs. $M=3.49)$. With respect to ratings of the need to punish the tortfeasor's actions, the meritocracy and type-of-tort variables again exerted main effects: the tortious actions were seen as less deserving of punishment in Society Zero than in Society One Hundred $(M=3.99$ vs. $M=3.33)$, and the intentional tort was seen as more deserving of punishment than the unintentional tort ( $M=2.49$ vs. $M=4.83$ ). Finally, with respect to the deterrent value of forcing the tortfeasor to compensate for the victim’s harm, participants judged imposition of a compensation duty to have greater deterrent value when applied to the intentional tort than unintentional tort $(M=4.83$ vs. $M=3.96)$.

Insert Table 3 about here

Consistent with the findings from the prior two experiments, scores on these dependent measures explained very little of the variance in compensation judgments. In only one condition 
did ratings on any of the secondary dependent measures significantly predict compensation judgments: when the poor man committed an act of negligence in Society Zero with a social insurance fund available, persons who saw less need for punishment of the act were significantly more likely to refrain from imposing a compensation duty (i.e., each one unit change in punishment rating toward less need for punishment increased the odds significantly that the participant would not impose a compensation duty), $\beta=2.75($ S.E. $=1.25), W(1)=4.82, p=.03$, $\exp (\beta)=15.57$

\section{Individual Differences}

Half of the participants (11/22) imposed a compensation duty in all four of the conditions in which social insurance was not available, which is comparable to the percentage found for the original compensation judgments in Experiment 1 (52.8\% imposed a compensation duty in all conditions when private insurance was not at issue in Experiment 1). Adding to the count the conditions in which social insurance was available results in only a slight reduction in the number of participants who imposed a compensation duty across all conditions (10/22, or 45.5\%, did so), which is less than the reduction seen in Experiment 1 when private insurance was added to the mix (the percentage of consistent compensation judgments dropped to $33.3 \%$ when private insurance was available). Thus, we replicated Experiment 1's finding that a substantial subset of the participant sample behaved in a manner consistent with a strict independence view of corrective justice.

We replicated Experiment 1 in another respect. Although we found no correlation between answers to demographic and political attitude questions and individual counts of the numbers of times that a compensation duty was imposed, which serves as a rough measure of sensitivity to background conditions, the composite political ideology measure significantly 
predicted compensation judgments, with more conservative respondents being more likely to impose a compensation duty, $\beta=-.18$ (S.E. $=.08), W(1)=5.36, p=.02, \exp (\beta)=.83$. However, the composite political ideology measure also interacted with meritocracy, $\beta=.15$ (S.E. $=.05$ ), $W(1)=10.67, p<.01, \exp (\beta)=1.16$, and type of tort, $\beta=.21$ (S.E. $=.05), W(1)=18.17, p<$ $.01, \exp (\beta)=.24$, and these interactions reveal that our sample of Democrats was, under some conditions, more likely to impose a compensation duty than the sample of Republicans:

Democrats imposed a compensation duty more frequently for both negligence (61\% v. 56\%) and conversion (100\% v. 89\%), and in Society Zero (79\% v. 58\%) (in Society One Hundred, Republicans imposed compensation $86 \%$ of the time compared to Democrats doing so $82 \%$ of the time). ${ }^{37}$

\section{Discussion}

We found some truth in both the independence and interdependence views of corrective justice but no truth in a strong distributive priority view. Strictly speaking, the independence position was rejected, because a good number of individuals did show sensitivity to background distributive conditions in all three experiments. For these people, the applicability of the corrective justice principle appears to depend on the nature of the tort in question, the wealth of the tortfeasor, the justice of the underlying distribution of wealth, and, to some slight extent, the existence of other mechanisms for compensating the victim. However, a considerable number of individuals exhibited compensation judgments in line with a strong independence view of corrective justice. For these people, the tortfeasor had a duty to right the wrong done to the victim regardless of the intentionality of the harmful act, regardless of the relative wealth of the

\footnotetext{
37 The compensation judgments of self-identified Independents more closely resembled those of Republicans than Democrats: Independents imposed a compensation duty $63 \%$ of the time for negligence and $88 \%$ of the time for conversion, and they imposed a compensation duty 63\% of the time for Society Zero and $88 \%$ of the time for Society One Hundred.
} 
parties, regardless of the justice of the society, and regardless of other means of compensating the victim. Therefore, it appears that laypersons, just like legal philosophers, differ in their views about the proper relation of corrective justice to distributive justice.

The disagreements among our participants should not overshadow the fact that we often found virtual unanimity in favor of enforcing the corrective justice norm: participants almost uniformly judged torts committed by the rich man, whether intentional or unintentional, and intentional torts occurring under conditions of moderate to perfect distributive justice to require correction through tortfeasor compensation to the victim. The fact that participants almost uniformly imposed a compensation duty on the rich tortfeasor who harmed the poor victim should not be seen as support for some version of a “deep pockets” hypothesis regarding liability judgments. Indeed, though extrapolations from the compensation judgments of our experimental participants to the liability judgments of actual jurors are extremely perilous, if anything, our results reject what might be called an “empty pockets” hypothesis predicting that jurors would be less likely to impose liability on poor persons. In our experiments, poverty was not a sufficient condition for being excused from a compensation duty after a tort had been committed; only when poverty was due to extremely unjust societal conditions did any significant percentage of the participants excuse the poor tortfeasor from the obligation to compensate the rich victim.

Furthermore, unintentional torts committed under conditions of moderate to perfect distributive justice elicited extremely high rates of agreement that justice required the tortfeasor to compensate the victim. We found this convergent behavior consistent with the corrective justice norm despite divergent views on the tortious acts' harmfulness, wrongfulness, need for punishment, and susceptibility to deterrence. 
To put it differently, participants widely disagreed about the applicability of the corrective justice norm only when a society was patently and extremely unjust (Societies Zero and Blue) or when social justice was ambiguous and other means of compensating the victim existed (Society Half with private insurance coverage available). A smaller, but significant, percentage of participants were also willing to diverge from the majority view and not impose a compensation duty on the poor tortfeasor who committed acts of negligence in the moderately and perfectly just societies (Societies Half and One Hundred). Thus, we see varying levels of adherence to the interdependence view of corrective justice depending on the nature of the background conditions: for a large percentage of the participant pool, extreme distributive injustice constrained corrective actions directed at the tortfeasor, and, for a smaller percentage, an alternative means of compensating the victim constrained corrective actions directed at the tortfeasor.

This finding suggests two corrective justice types—corrective justice “diehards” who treat fulfillment of corrective justice as a trump value and corrective justice "contextualists” who strongly favor corrective justice but who are willing to trade fulfillment of corrective justice off against distributive justice or who are willing to allow other compensation mechanisms to sate their desire for corrective justice—and presents at least two interesting questions for future research. First, how robust is this typology? We were necessarily limited in the range of torts and situations that we could experimentally study. We focused on harms to personal property, and it remains to be seen whether harms to the person would elicit the same responses, particularly from corrective justice contextualists. Moreover, the harms that were excused by the contextualists could be deemed quite minor, since they were predominantly the harms by the 
poor man against the fabulously wealthy man. The generality of this contextualist orientation could thus be tested by altering the type and magnitude of the harm perpetrated.

It should be noted, nevertheless, that we failed to find a significant relationship between perceptions of harm done and compensation judgments. A stronger test of this relationship would treat harm as an independent variable, comparing the effect of harms that vary considerably in magnitude on compensation judgments. And while changing the type or magnitude of the tortious harms might further decrease the impact of the distributive justice manipulations, it is also possible to imagine even more compelling distributive justice manipulations than those employed here. For instance, one can imagine a world in which two rigidly separated classes exist, with the rich truly filthy rich and the poor appallingly poor and in which the rich brutally oppress and exploit the poor. Perhaps the distributive injustice must be this stark to overcome the power of the corrective justice instinct or to rouse sentiment among members of modern democratic societies for moves toward distributive justice.

Also in regard to robustness, our use of a binary variable as the main dependent measure may have masked differences within the two groups of respondents that a continuous variable might have revealed. We favored this binary dependent measure nevertheless because it forced subjects to make the tough decision of imposing a compensation duty on the tortfeasor or not; asking subjects to rate a tortfeasor's duty to compensate on a multipoint scale would have allowed subjects to retreat to the middle of the scale in tough cases, possibly using the midpoint as a form of "don’t know" response..$^{38}$ Thus, while use of a continuous dependent measure would arguably have made our statistical tests more sensitive and thus more likely to reject the

\footnotetext{
${ }^{38}$ Cf. Jon A. Krosnick \& Leandre R. Fabrigar, Designing Rating Scales for Effective Measurement in Surveys, in SuRVey Measurement AND PROCESS QUALITY 141 ( Lars E. Lyberg et al. eds., 1997) (discussing the ambiguity of midpoint response categories); Quiten A. W. Raaijmakers et al., Adolescents' Midpoint Responses on Likert-Type Scale Items: Neutral or Missing Values?, 12 InT’L J. PuB. OPINION Res. 208 (2000).
} 
null hypotheses, greater sensitivity here does not necessarily mean better tests of the competing theoretical positions. Because we were more interested in the relative fit of the different theories with the pattern of responses than with testing the null hypotheses, we concluded that forcing the dichotomous choice would yield a clearer test of subjects' relative commitment to distributive versus corrective justice.

Second, are there reliable individual-level predictors of who is a corrective justice diehard or contextualist? Although we tested several demographic and other individual difference variables, only measures of political ideology consistently shed any light on why individuals differ in their corrective justice orientations. Results of the second experiment in particular suggested the difference arose from factors related to political ideology, but the difference found there between Democrats and other groups could be an artifact of the particular distributive justice manipulation used, rather than an indication of different basic orientations to corrective justice among political groups. ${ }^{39}$ Therefore, an interesting avenue for future work will be to try to identify more definitively whether differences in political ideology and political motivations consistently translate into differences in corrective justice orientations. ${ }^{40}$ It may be that differential activation of intuitive versus analytical thought processes account for the relatively stronger impact of corrective justice, with intuitions about corrective justice tending to dominate in tort settings due to the specific and concrete nature of the harms done except among

\footnotetext{
${ }^{39}$ An interesting possibility suggested by an anonymous reviewer is that, under conditions of ambiguity regarding responsibility for a tort, liberals and conservatives may resolve the ambiguity differently depending on the level of societal meritocracy and the wealth of the alleged tortfeasor and victim. We found some evidence for this biased assimilation/motivated reasoning process in earlier research. See Mitchell et al., Compromises, supra note 24. In this study, we specified by fiat that negligence or conversion had occurred to avoid this very possibility, but this ambiguity manipulation merits further study since ambiguity about responsibility often surrounds real world torts.

${ }^{40}$ Another individual difference hypothesis suggested by reviewers of the paper, but not tested here, is that religious orientation and religiosity would predict corrective justice orientation, with adherents of more fundamentalist, "eyefor-an-eye” religions being more likely to be corrective justice diehards. It could also be the case that adherents of certain religions would be predisposed to emphasize distributive over corrective justice. $C f$. Susan Pace Hamill, $A n$ Argument for Tax Reform Based on Judeo-Christian Ethics, 54 ALA. L. REV. 1, 75-76 (2002).
} 
those socialized in a more egalitarian social system or those strongly committed to egalitarian goals over all rivals. If so, then use of a survey design involving larger and more diverse participant samples would be a better vehicle for examining these individual differences than our within-subjects experimental approach, and cognitive-load manipulations might help to identify which intuitive response is more primitive. ${ }^{41}$

This second question relates to a larger puzzle presented by the experiments: exactly what are people trying to achieve when they impose a compensation duty on a tortfeasor? Of course, one answer, and perhaps the best one to explain our findings, is corrective justice as an end in itself. In most cases, compensation judgments did not appear motivated by deterrence concerns, a finding consistent with that found by Baron and Ritov, ${ }^{42}$ nor were compensation judgments used as a means to compensate the faultless victim only in the absence of social or private insurance. Thus, a parsimonious explanation for the pattern of behavior we observed is that it reflects application of the norm that a wrongdoer has a duty to correct a harm done.

However, attitudes about the tortious acts’ wrongfulness and need for punishment did relate to compensation judgments in what might be called the hard cases that most deeply divided respondents' judgments, namely, acts of negligence occurring in Societies Zero and Half and the act of conversion occurring in Society Blue. Furthermore, intentional torts were consistently seen as more wrongful and consistently elicited higher percentages of judgments imposing a compensation duty than unintentional torts. The typical theoretical distinction between corrective and retributive justice is that corrective justice corrects losses or harms,

\footnotetext{
41 For instance, we might predict that a cognitive-load manipulation would have no effect on the application of corrective justice principles but disrupt the application of distributive justice principles among all but the most egalitarian. On dual-process theories generally, see DuAL-Process THEORIES IN SOCIAL PsYCHOLOGY (Shelly Chaiken \& Yaacov Trope eds., 1999).

${ }^{4}$ See Baron \& Ritov, supra note 21, at 31.
} 
whereas retributive justice punishes wrongful acts regardless of their harms. ${ }^{43}$ It may be, therefore, that both corrective justice diehards and corrective justice contextualists saw the imposition of liability on the tortfeasor as a form of retribution for a civil wrong, but the thresholds at which their desire for retribution was triggered differed. If that were the case, then retributive justice would be prior to corrective justice, or rather corrective justice is a means to retributive justice. Although we must leave it to future experiments to unconfound retributive and corrective justice, our findings suggest that it would be a useful exercise, because it appears that acts of retributive justice may occasionally masquerade as acts of corrective justice. ${ }^{44}$

Before concluding, two additional limitations on the studies merit mention. First, one may quarrel with our characterization of distributive (in)justice. We discount the seriousness of this limitation, however, because we constructed the hypothetical societies and the main dependent measure in such a way that participants who emphasized distributive justice over corrective justice-whether they endorsed a need-based, equality-based, or desert-based theory of distributive justice —-would give the same response: judge the tortfeasor to have no obligation to compensate the victim. Indeed, we constructed the hypothetical societies to make clear that the poor tortfeasors (John Dover and John Purple) were always in serious need (as they were living below the poverty line), were in an unequal economic position relative to the much richer victim, and in Societies Zero and Blue were being unjustly kept at the lowest rung of society. In

\footnotetext{
${ }^{43}$ See, e.g., Alan CALnAN, JustiCE AND TORT LAW 112 (1997).

${ }^{44}$ Recent work by Fehr and colleagues suggests that a retaliatory motive, similar to a retributive motive, may be at work: norm violation often elicits retaliation in cooperation games, and the retaliation seems aimed at punishment rather than correcting an imbalance in payoffs, because "[t]he evidence suggests that the desire to re-establish equality does not drive the majority of non-selfish sanctions.” Ernst Fehr \& Urs Fischbacher, Social Norms and Human Cooperation, 8 TREnds IN CoG. SCI. 185, 188 (2004); see also Armin Falk et al., Driving Forces Behind Informal Sanctions, 73 EconOMETRICA 2017 (2005); Philip E. Tetlock et al., People as Intuitive Prosecutors: The Impact of Social Control Motives on Attributions of Responsibility, 42 JOURNAL OF EXPERIMENTAL SOCIAL PSYCHOLOGY (forthcoming 2006).
} 
other words, we ensured that common conceptions of social justice and corrective justice were not confounded. Therefore, the experiments still succeed as tests of whether concerns about righting distributive injustice will override corrective justice concerns, even if one does not endorse the desert-based view of distributive justice.

Second, our participant pool, though quite diverse politically and gender-wise, consisted mostly of European Americans, and the pool itself (but not the number of observations) was small due to the use of within-subjects designs. Other research has found cultural differences in moral reasoning, suggesting that a more culturally or ethnically diverse sample might have produced a different patterns of results. ${ }^{45}$ Also, the use of law students as the objects of study meant that the participants likely had a greater familiarity with the corrective justice theory of torts than the general public does. However, as Goldberg notes, the traditional approach to tort law found in most law school casebooks does not emphasize corrective justice theory, and there is no reason to believe that the law students who participated in our experiments had been encouraged to see torts primarily through a corrective justice lens. ${ }^{46}$ Nevertheless, only further tests can tell whether a different and more diverse sample would yield the same results.

\section{Conclusion}

The experiments reported here represent the first systematic empirical comparison of the relation of corrective justice to distributive justice. Despite the social and political importance of

\footnotetext{
${ }^{45}$ See, e.g., Wulf Gaertner, Jochen Jungeilges \& Reinhard Neck, Cross-cultural Equity Evaluations: $A$ Questionnaire-experimental Approach, 45 EuR. ECON. REV. 953, 963 (2001); Joan G. Miller \& David M. Bersoff, Culture and Moral Judgment: How Are Conflicts Between Justice and Interpersonal Responsibilities Resolved?, 62 J. PERSONALITY \& SOCIAL PSYCHOL. 541, 551 (1992).

${ }^{46}$ See Goldberg, supra note 1, at 575. Conversations with tort law professors at Florida State University confirmed that participants in the study were not taught torts from a predominantly corrective justice perspective, though participants were likely exposed to corrective justice theory along with other theories of tort during their first-year class in torts.
} 
this relationship, ${ }^{47}$ it has received little study within the field of empirical justice research. The strong sense of corrective justice expressed by the participants in our experiments may partially explain public opposition to moves toward no-fault liability, publicly-funded victim compensation funds or other administrative schemes designed to be more efficient than the common law tort system, and our findings suggest strong support for the present tort system as a system for allocating the costs of accidents and intentional civil wrongs between individuals, if not as a mechanism for social reform. It seems to be the case, as Stephen Perry intuits, that within the mind of the public, changing the nature of the tortfeasor-victim relationship is not a particularly good vehicle for righting social injustices. ${ }^{48}$ That is, our results indicate that absolving the tortfeasor of personal responsibility for wrongful actions will only rarely be a politically viable means to correcting social injustice. ${ }^{49}$ Or to put it in terms of an amendment to an old saw: most of the time, two wrongs do not make a right, but for some people occasionally distributive injustice is so great that a second wrong does in fact make a right.

\section{Supplementary Material}

The experimental materials used in the studies reported here are available on request from the first author.

\footnotetext{
${ }^{47}$ See Jules Coleman \& Arthur Ripstein, Mischief and Misfortune, 41 McGILL L.J. 91, 98 (1995).

48 See Perry, supra note 3, at 261; see also John C.P. Goldberg, Tort Law for Federalists (and the Rest of Us): Private Law in Disguise, 28 HARV. J.L. \& PuB. POL’Y 3 (2004).

49 This is particularly true since most participants rated American society as most similar to Society Half in Experiment 1 (91.7\%), most similar to Society Beige in Experiment 2 (95.8\%), and most similar to Society One Hundred in Experiment 3 (63.6\%) (recall that in Experiment 3, participants compared the United States to only Societies Zero and One Hundred, as Society Half was not included in the third experiment). Thus, few perceived American society in terms of the extreme distributive injustice that merited departures from corrective justice in Society Zero and Society Blue. Nevertheless, as Jeff O’Connell points out, workers do not seem to rebel greatly against no-fault workers compensation schemes, and some no-fault accident insurance systems have been fairly well received in some states, see Jeffrey O’Connell \& Christopher J. Robinette, “Choice Auto Insurance”: Do Theories of Justice Require Linkage Between Injurers and the Injured?, 1997 U. ILL. L. REV. 1109. Thus, an important project for tort reformers should be to better understand the conditions under which fault and no-fault systems are acceptable.
} 
Figure 1

\section{Experiment 1: Percent Imposing Compensation Duty on Tortfeasor}

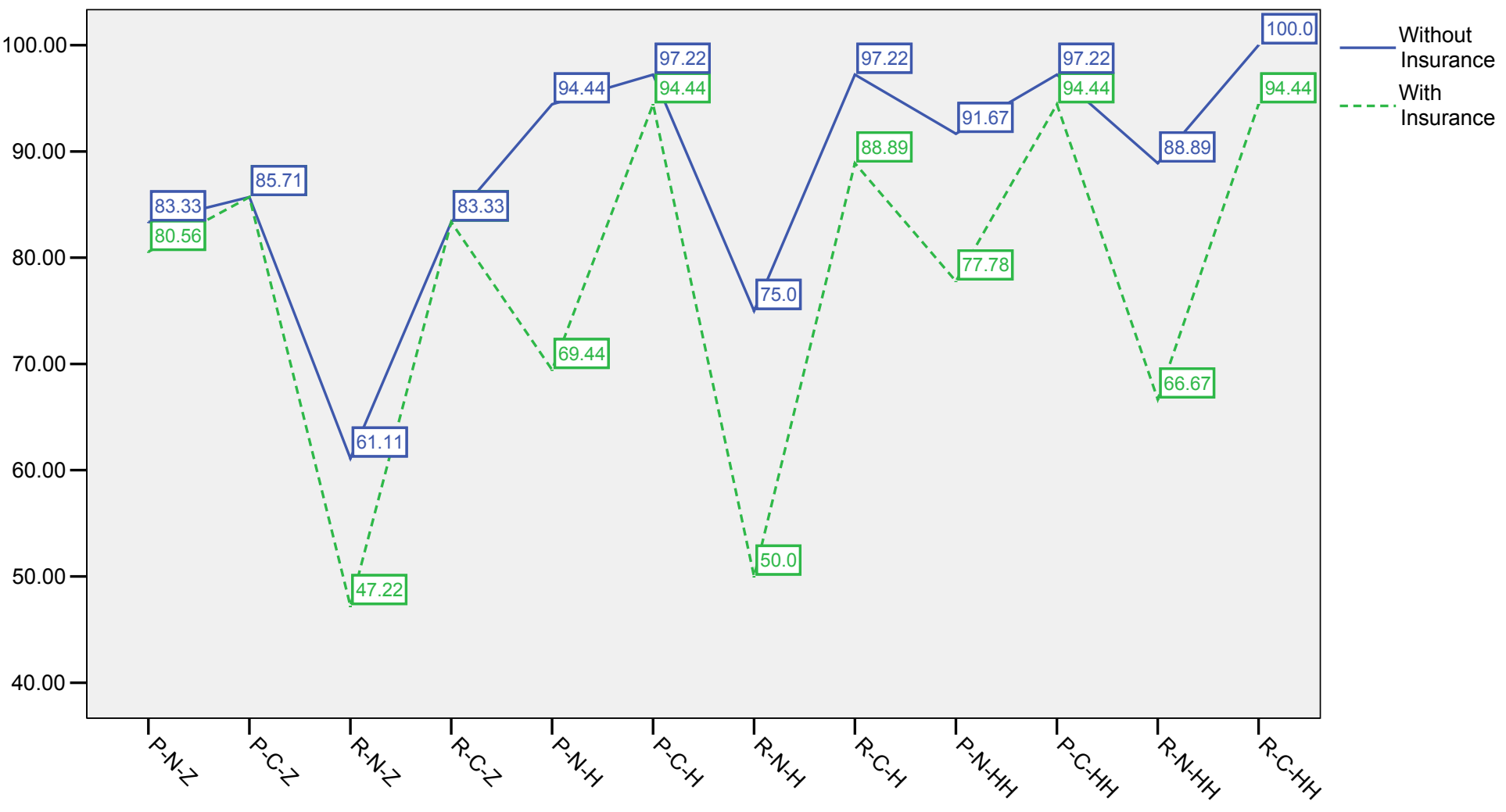

Note: P=Poor Victim, R=Rich Victim; N=Negligence, C=Conversion; Z=Society Zero, H=Society Half; HH=Society One Hundred. The solid, "Without Insurance" line represents judgments made without about the availability of private insurance, whereas the dashed, "With Insurance" line represents judgments made when private insurance existed. 
Figure 2

\section{Experiment 2: Percent Imposing Compensation Duty on Tortfeasor}

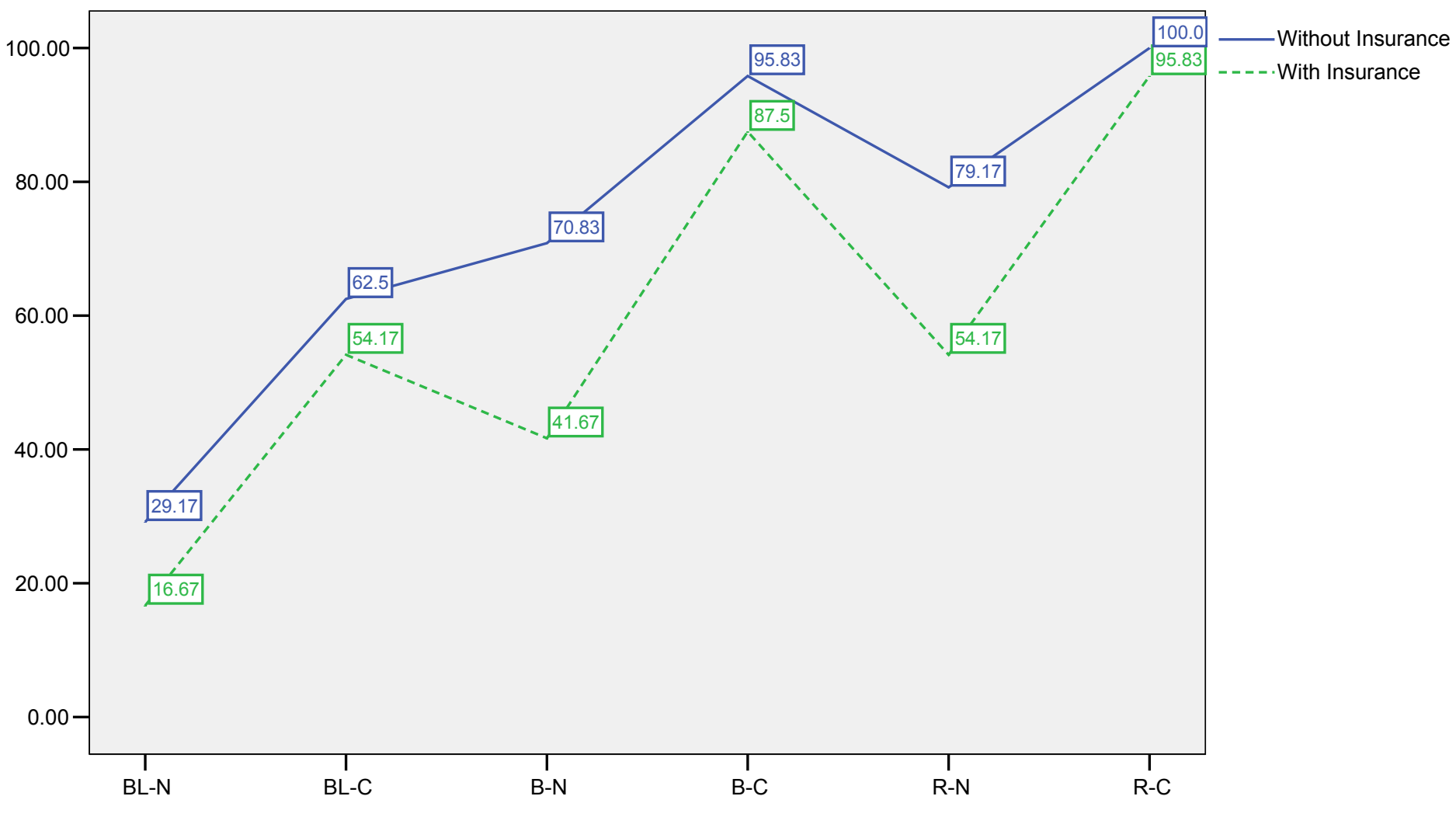

Note: $\mathrm{BL}=$ Society Blue, $\mathrm{B}=$ Society Beige, $\mathrm{R}=$ Society Rainbow; $\mathrm{N}=$ Negligence, $\mathrm{C}=$ Conversion. The solid, "Without Insurance" line represents judgments made without information about the availability of private insurance, whereas the dashed, "With Insurance" line represents judgments made when private insurance existed. 
Figure 3

\section{Experiment 3: Percent Imposing Compensation Duty on Tortfeasor}

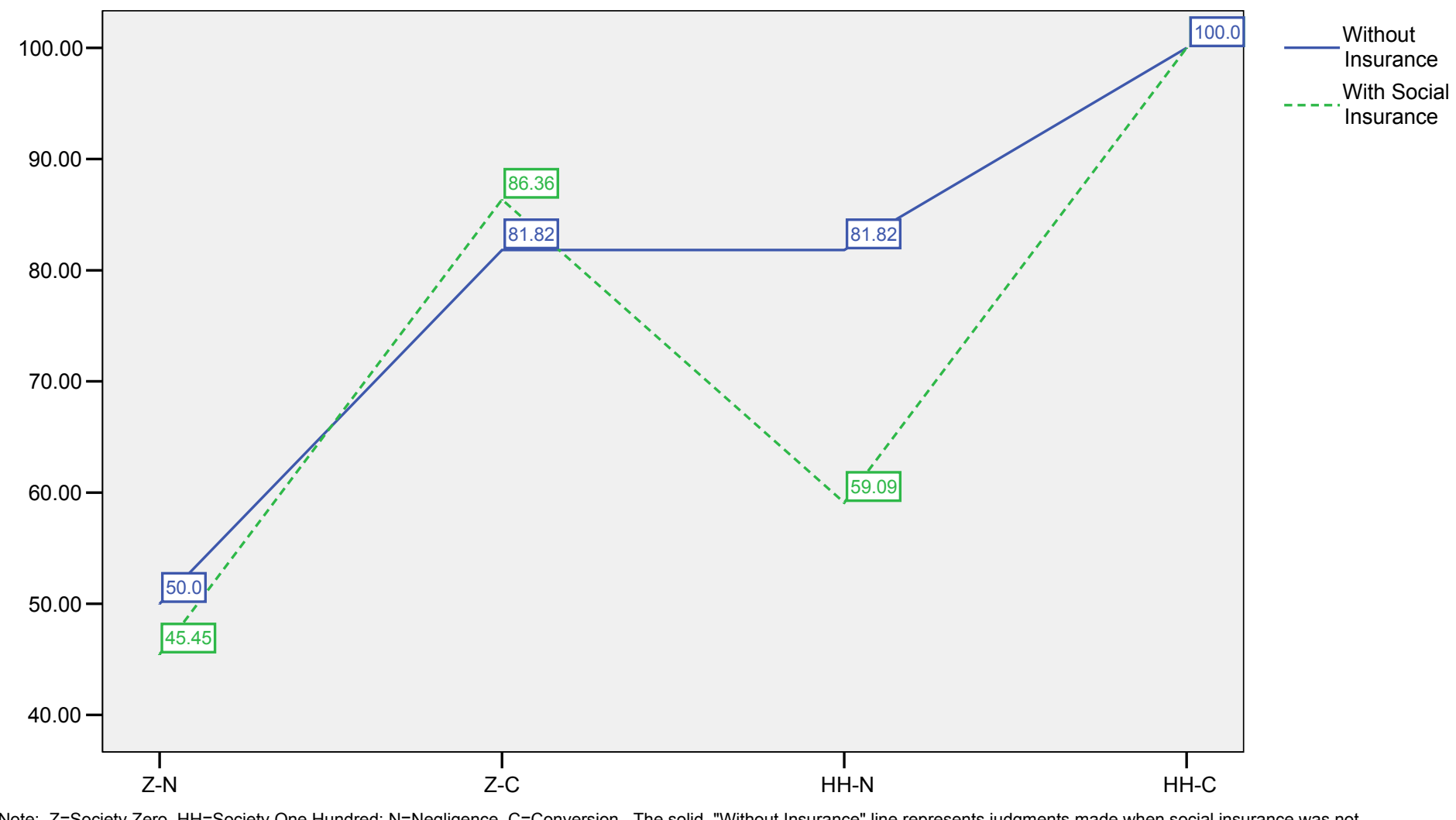

Note: $\mathrm{Z}=$ Society Zero, $\mathrm{HH}=$ Society One Hundred; $\mathrm{N}=$ Negligence, $\mathrm{C}=$ Conversion. The solid, "Without Insurance" line represents judgments made when social insurance was not available, whereas the dashed, "With Social Insurance" line represents judgments made when social insurance was available to cover the tortious harm. 
Table 1

Experiment 1: Results of Analyses of Variance on Secondary Dependent Variables

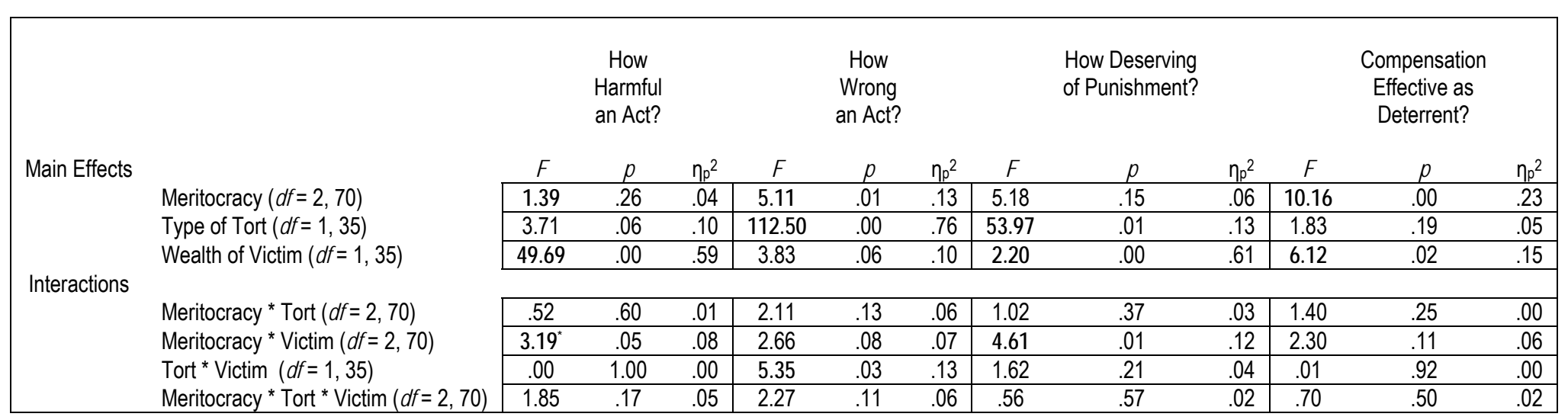

Bolded $F$ values are significant at the $p<.05$ level or lower. This table reports the results of repeated-measures analyses of variance examining main and interaction effects of the independent variables on each of the secondary dependent measures. In addition to $F$ values and level of significance $(p)$, the table also reports the partial eta squared $\left(\eta_{p}{ }^{2}\right)$, an estimate of effect size, associated with each main and interaction effect.

${ }^{*}$ Reported $F$ values for all experiments assume sphericity (i.e., homogeneity of treatment difference variances). In a few instances, tests revealed that this assumption was violated; in these instances, the Greenhouse-Geiser and Huynh-Feldt corrections were employed to produce more accurate significance ( $p$ ) values. Across all experiments, the only effect for which violation of the sphericity assumption altered the statistical significance of the reported $F$ value was the meritocracy by wealth-of-the-victim interaction in Experiment 1, although this effect was marginally significant after corrections were made (Greenhouse-Geiser and Huyhn-Feldt $F=3.185, p<.06)$. 
Table 2

Experiment 2: Results of Analyses of Variance on Secondary Dependent Variables

\begin{tabular}{|c|c|c|c|c|c|c|c|c|c|c|c|c|c|}
\hline \multirow{3}{*}{ Main Effects } & & \multirow[b]{2}{*}{$F$} & \multicolumn{2}{|c|}{$\begin{array}{l}\text { How } \\
\text { Harmful } \\
\text { an Act? }\end{array}$} & \multicolumn{3}{|c|}{$\begin{array}{l}\text { How } \\
\text { Wrong } \\
\text { an Act? }\end{array}$} & \multicolumn{3}{|c|}{$\begin{array}{l}\text { How Deserving } \\
\text { of Punishment? }\end{array}$} & \multicolumn{3}{|c|}{$\begin{array}{c}\text { Compensation } \\
\text { Effective as } \\
\text { Deterrent? }\end{array}$} \\
\hline & & & $p$ & $\eta_{p}^{2}$ & $F$ & $p$ & $\eta_{p}^{2}$ & $F$ & $p$ & $\eta_{p}^{2}$ & $F$ & $p$ & $\eta_{p}^{2}$ \\
\hline & Meritocracy $(d f=2,46)$ & 8.43 & .00 & .27 & 9.70 & .00 & .30 & 15.50 & .00 & .40 & 5.05 & .01 & .18 \\
\hline & Type of Tort $(d f=1,23)$ & .03 & .87 & .00 & 68.75 & .00 & .75 & 27.53 & .00 & .55 & 1.88 & .18 & .08 \\
\hline \multicolumn{14}{|l|}{ Interaction } \\
\hline & Meritocracy ${ }^{*}$ Tort $(d f=2,46)$ & 2.23 & .12 & .09 & 3.30 & .05 & .13 & 1.19 & .31 & .05 & .22 & .80 & .01 \\
\hline
\end{tabular}

Note: Bolded $F$ values are significant at the $p<.05$ level or lower. This table reports the results of repeated-measures analyses of variance examining main and interaction effects of the independent variables on each of the secondary dependent measures. In addition to $F$ values and level of significance ( $p$ ), the table also reports the partial eta squared $\left(\eta_{p}^{2}\right)$, an estimate of effect size, associated with each main and interaction effect. 
Table 3

Experiment 3: Results of Analyses of Variance on Secondary Dependent Variables

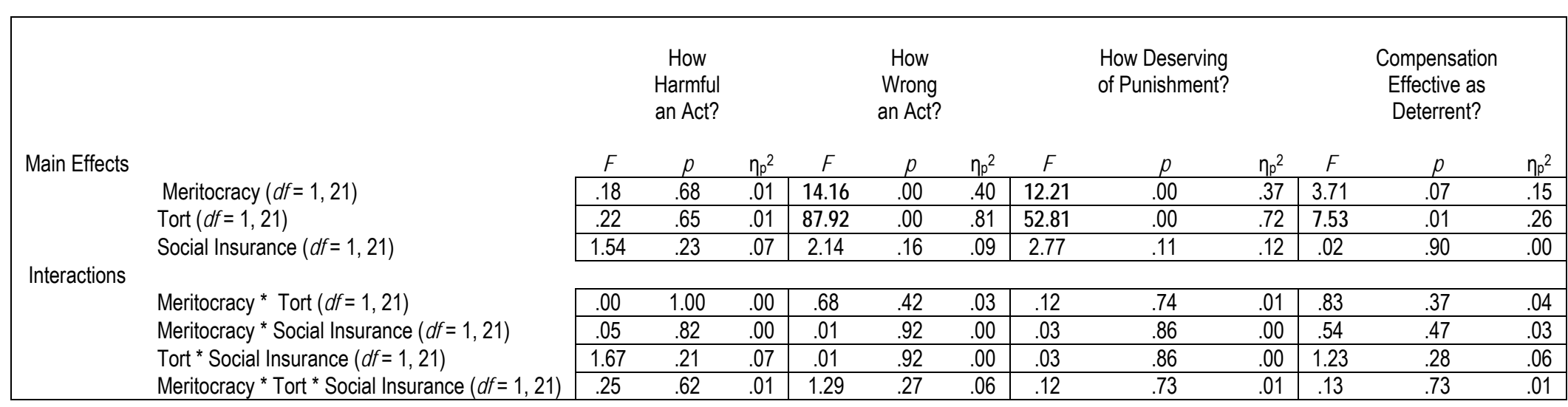

Note: Bolded $F$ values are significant at the $p<.05$ level or lower. This table reports the results of repeated-measures analyses of variance examining main and interaction effects of the independent variables on each of the secondary dependent measures. In addition to $F$ values and level of significance ( $p$ ), the table also reports the partial eta squared $\left(\eta_{\mathrm{p}}{ }^{2}\right)$, an estimate of effect size, associated with each main and interaction effect. 